\title{
Multi-Scale Modeling of Thermal-Fluid Phenomena Related to Loss of Forced Circulation Transient in HTGRs
}

Nuclear Science and Engineering Division 


\begin{abstract}
About Argonne National Laboratory
Argonne is a U.S. Department of Energy laboratory managed by UChicago Argonne, LLC under contract DE-AC02-06CH11357. The Laboratory's main facility is outside Chicago, at 9700 South Cass Avenue, Argonne, Illinois 60439. For information about Argonne and its pioneering science and technology programs, see www.anl.gov.
\end{abstract}

\title{
DOCUMENT AVAILABILITY
}

Online Access: U.S. Department of Energy (DOE) reports produced after 1991 and a growing number of pre-1991 documents are available free via DOE's SciTech Connect (http://www.osti.gov/scitech/)

\author{
Reports not in digital format may be purchased by the public from the \\ National Technical Information Service (NTIS): \\ U.S. Department of Commerce \\ National Technical Information Service \\ 5301 Shawnee Rd \\ Alexandra, VA 22312 \\ www.ntis.gov \\ Phone: (800) 553-NTIS (6847) or (703) 605-6000 \\ Fax: (703) 605-6900 \\ Email: orders@ntis.gov \\ Reports not in digital format are available to DOE and DOE contractors from the \\ Office of Scientific and Technical Information (OSTI): \\ U.S. Department of Energy \\ Office of Scientific and Technical Information \\ P.O. Box 62 \\ Oak Ridge, TN 37831-0062 \\ www.osti.gov \\ Phone: (865) 576-8401 \\ Fax: (865) 576-5728
}

\begin{abstract}
Disclaimer
This report was prepared as an account of work sponsored by an agency of the United States Government. Neither the United States Government nor any agency thereof, nor UChicago Argonne, LLC, nor any of their employees or officers, makes any warranty, express or implied, or assumes any legal liability or responsibility for the accuracy, completeness, or usefulness of any information, apparatus, product, or process disclosed, or represents that its use would not infringe privately owned rights. Reference herein to any specific commercial product, process, or service by trade name, trademark, manufacturer, or otherwise, does not necessarily constitute or imply its endorsement, recommendation, or favoring by the United States Government or any agency thereof. The views and opinions of document authors expressed herein do not necessarily state or reflect those of the United States Government or any agency thereof, Argonne National Laboratory, or UChicago Argonne, LLC.
\end{abstract}




\section{Multi-Scale Modeling of Thermal-Fluid Phenomena Related to Loss of Forced Circulation Transient in HTGRs}

prepared by

Prasad Vegendla, Rui Hu, Ling Zou

Nuclear Science and Engineering Division, Argonne National Laboratory

September 2019 



\section{EXECUTIVE SUMMARY}

Under the support of DOE-NE's Nuclear Energy Advanced Modeling and Simulation (NEAMS), an effort had been pursued to support High Temperature Gas-cooled Reactors (HTGR) technology development and its modeling and simulation needs. There was a particular need for advanced modeling \& simulation tools to predict thermal-fluid behavior in the nuclear reactor primary system, especially the core and lower and upper plena, during safety-related transients. In this report, two main such activities were presented: 1) system level HTGR simulations using system analysis code SAM for both normal operating and accident conditions; and 2) three-dimensional (3D) computational fluid dynamics (CFD) simulations on Deteriorated Turbulent Heat Transfer (DTHT) of interest to HTGR transients, including code benchmark and closure correlation development.

In this work, Modular High Temperature Gas-cooled Reactor (MHTGR) full loop simulations were performed using System Analysis Module (SAM) code. Two approaches were used to model the reactor core; (i) unit-cell or lumped parameter model, and (ii) detailed ring model, to address the different needs under different reactor conditions. Aside from the core model changes other reactor components in the primary system, such as upper/lower plenum, heat exchanger and blower etc, were kept the same.

In the unit-cell core model, the lumped parameter approach was used to model the coolant channels and the heat structures using 1-D and 2-D components, respectively. The fuel assembly heat structure was modeled based on unit-cell thickness approximation. In normal and controlled operating conditions, the calculated maximum temperatures for both coolant and heat structures were within the designed limits. The unit-cell model is, however, not able to capture the radial heat conduction through fuel assemblies, which is the dominant heat transfer mechanism during accident transients, such as pressurized conduction cooldown (PCC) event. To address this modeling challenge, ring models were developed.

A simplified ring model was developed first. In this simplified model, the active core was simulated with 9 circular rings consists of 6 rings for homogenized fuel heat structure and 3 rings for gas coolant. It was quickly found that this model gives rather large simulation error as it was not able to correctly capture the solid structure representative geometries. A detailed ring model was developed to address this issue. The active core was simulated with 99 circular rings consists of 66 rings for homogenized fuel heat structure and 33 rings for gas coolant. In both ring models, six additional rings were included to represent inner reflector, outer reflector, core barrel, Reactor Pressure Vessel (RPV), RPV coolant channel, and Reactive Cavity Cooling System (RCCS).

The detailed ring model was applied in two different SAM simulations; (i) normal operating conditions, and (ii) accident scenarios (more specifically, PCC event), for MHTGR design. In both simulations, the SAM calculated results for coolant and heat structure temperatures were within the reactor designed limits. The newly proposed detailed ring model approach in this work has proved to be a promising method to address the challenging modeling and simulation needs in the MHTGR design. As demonstrated in this work, this model was suitable for MHTGR simulations under both normal and accident conditions. 
Apart from the SAM model development for gas-cooled reactors, 3D Computational Fluid Dynamics (CFD) models were developed and validated with relaminarized Deteriorated Turbulent Heat Transfer (DTHT) MIT benchmark test. Two different CFD codes, Nek5000 and STAR-CCM+, were used for this benchmark activity. Compared with MIT data, Nek5000 shows very good agreement between its simulated and experimentally measured wall temperatures. In contrast, STAR-CCM+ under-predicted wall temperature due to overpredicted turbulence in the wall region.

The Nek5000 code was also used to develop wall-heat transfer correlations for laminar flow in cylindrical tube. Several simulations were performed for various Reynolds flow and wallheat fluxes. Significant deviations were found when compared the predicted heat transfer coefficient and the Sieder-Tate correlation. A new set of heat transfer correlation was proposed for laminar flow which is valid for $400<\operatorname{Re}<2000$. 


\section{Table of Contents}

EXECUTIVE SUMMARY i

Table of Contents.................................................................................................. ii

List of Figures............................................................................................... iv

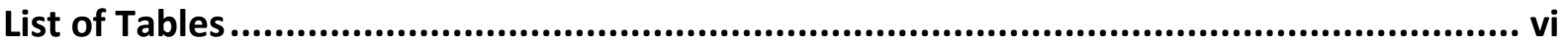

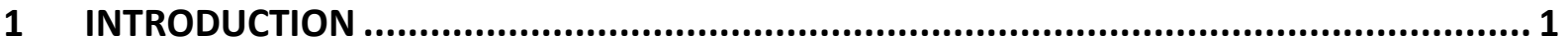

2 Modeling and Simulations of MHTGR Using SAM Code.......................................... 4

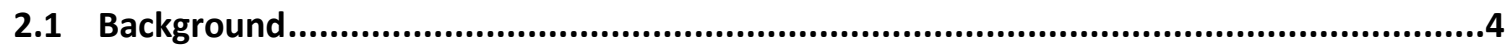

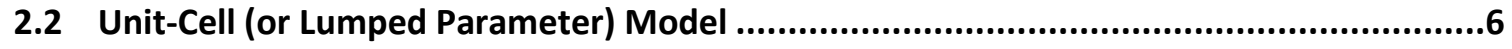

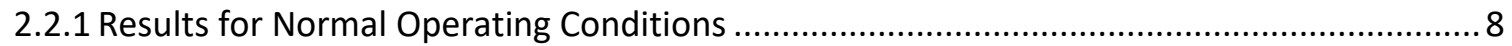

2.2.2 Simulation Results for Controlled Reactor Transients ................................................. 11

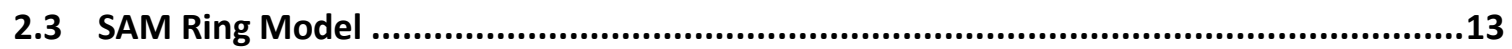

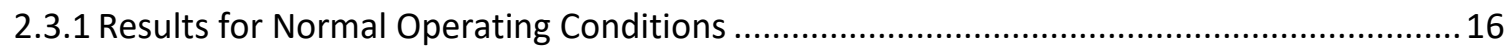

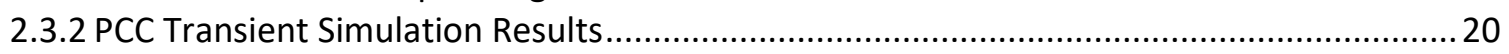

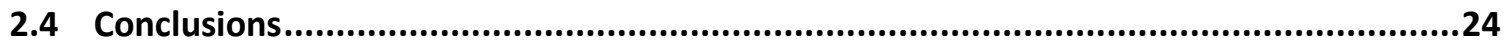

3 Modeling and Validation of Deteriorated Turbulent Heat Transfer in Wall Heated Cylindrical Tube ................................................................................................... 25

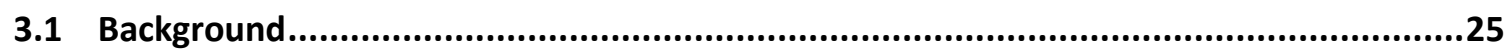

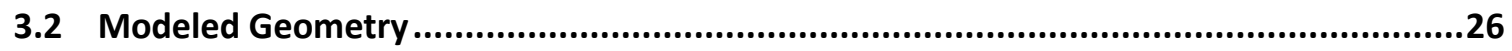

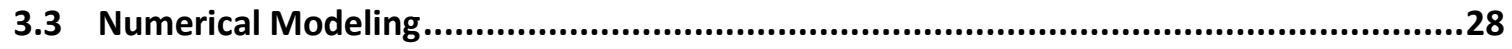

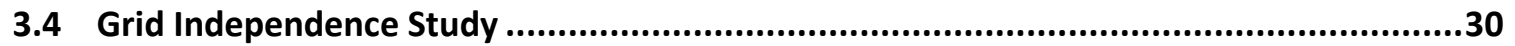

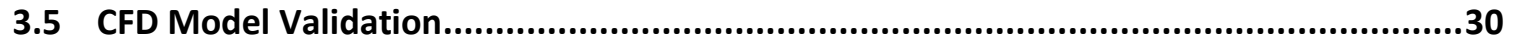

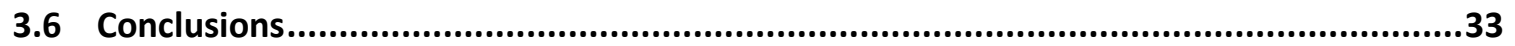

4 Development of Heat Transfer Correlations for Laminar Flow in Wall Heated

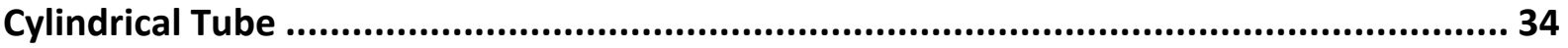

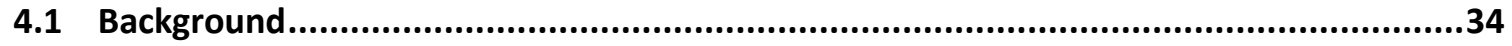

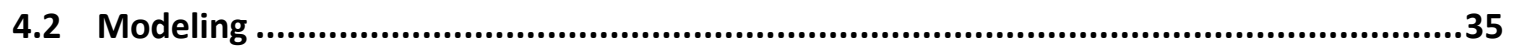

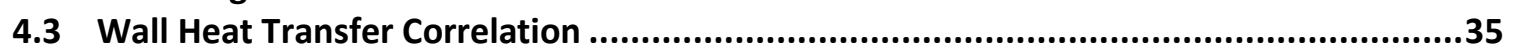

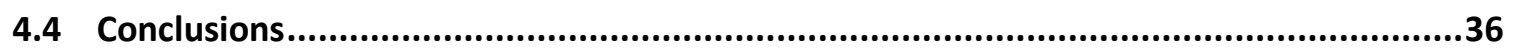

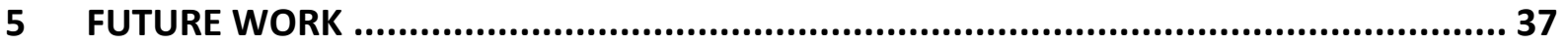

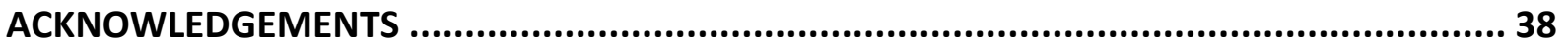

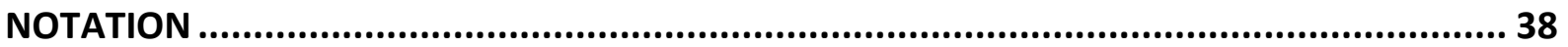

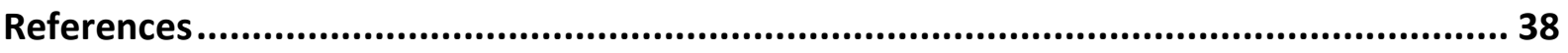

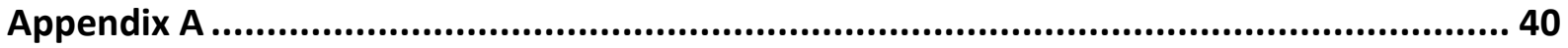




\section{LIST OF FIGURES}

Figure 1-1. HTGR (i) normal operating condition, (ii) natural circulation (yellow arrows) pathways during PCC event [1-2]

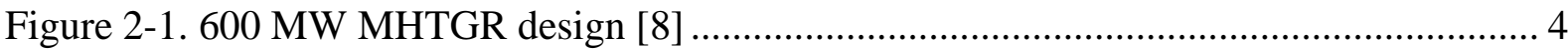

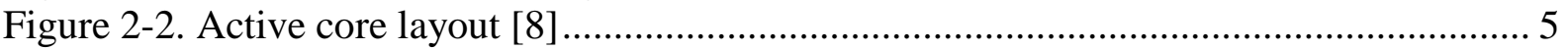

Figure 2-3. MHTGR Primary loop geometry .......................................................... 7

Figure 2-4. Power distribution axial profile for active core ............................................. 7

Figure 2-5. Fluid fields for (i) temperature and (ii) velocity................................................ 9

Figure 2-6. Solid temperature radial distribution at various axial location in a primary loop

Figure 2-7. Fluid profile along the axial length of the active core (i) Velocity and (ii)

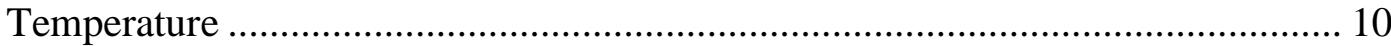

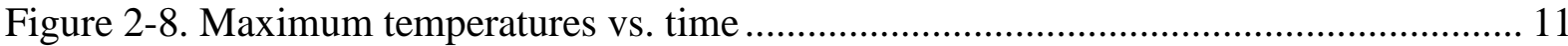

Figure 2-9. Controlled reactor transient profiles for power, pump head and heat exchanger secondary flow

Figure 2-10. Time profiles for (i) maximum temperatures, (ii) coolant temperature, (iii) coolant velocity, (iv) ratio of reactor power to heat exchanger removal and (v)

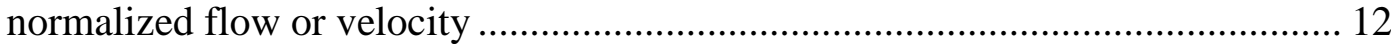

Figure 2-11. SAM model for primary loop (detailed ring model) ...................................... 14

Figure 2-12. MHTGR primary loop simulations in paraview; (i) Simplified ring model

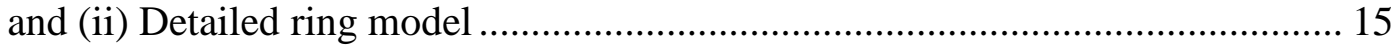

Figure 2-13. SAM model temperatures, (i) simplified ring and (iii) detailed ring ................. 16

Figure 2-14. Coolant fields for (i) Temperature and (ii) Velocity magnitude ........................ 17

Figure 2-15. Fluid and solid temperature distribution .................................................. 18

Figure 2-16. Active core coolant (i) Temperature and (ii) Velocity ................................... 18

Figure 2-17. Heat structure temperature across radial direction ........................................... 19

Figure 2-18. Maximum values for coolant (i) Temperature and (ii) Velocity ....................... 19

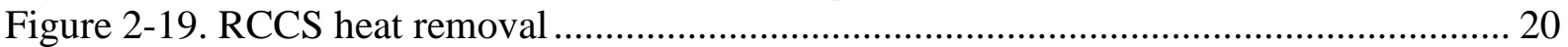

Figure 2-20. Power History for accident scenario [11] ................................................... 20

Figure 2-21. Heat structures maximum temperatures ................................................... 21

Figure 2-22. Coolant maximum values for (i) Temperature and (ii) Velocity....................... 22

Figure 2-23. Coolant channel velocities for (i) inner fuel ring, (ii) middle fuel ring, (iii) outer fuel ring and (iv) RPV ...................................................................... 22

Figure 2-24. Coolant channel temperatures for (i) inner fuel ring, (ii) middle fuel ring, (iii)

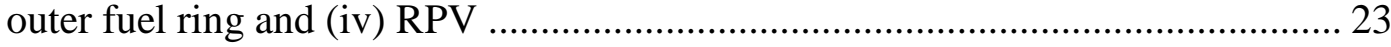

Figure 2-25. RCCS heat removal and reactor power ................................................. 23

Figure 3-1. Schematic diagram of DTHT benchmark test .............................................. 27

Figure 3-2. Modeled geometry for DTHT benchmark test; (i) STAR-CCM+ and (ii) Nek5000

Figure 3-3. DTHT cylindrical tube mesh on a vertical plane at center of the tube; (i) STAR$\mathrm{CCM}+$ polyhedral mesh and (ii) Nek5000 hexahedral mesh.... 
Figure 3-4. Comparison of wall temperatures along the axial direction of the test section for different mesh count for Run-6; (i) STAR-CCM+ and (ii) Nek5000 30

Figure 3-5. Comparison of Nek5000 and STAR-CCM+ results with experimental data along the axial direction of the test section; (i) Wall and bulk temperatures and (ii) Simulation error for wall temperature (experiment-simulation)....

Figure 3-6. Comparison of CFD codes (STAR-CCM+ and Nek5000) for turbulent viscosity across tube radius at various axial locations from test section inlet ....... 31

Figure 3-7. Nek5000 time averaged fields on XZ-plane (Y=0) for Run-6; (i) Velocity (m/s) and (ii) Temperature (K)

Figure 3-8. Nek5000 axial velocity profiles across radial direction at various axial locations in the test section for Run-6.

Figure 4-1. Nek5000 simulation data; (i) Nusselt Vs. Reynolds flow and (ii) Nusselt Vs. $\beta$ in a wall-heated cylindrical tube 36

Figure 4-2. Wall heat transfer correlations (Nusselt Vs. $\beta$ ), (i) $\operatorname{Re}>400 \& \operatorname{Re}<2000$ and

(ii) $\operatorname{Re} \leq 400$ and $\operatorname{Re} \geq 80$ 36 


\section{LIST OF TABLES}

Table 2-1. Fluid properties and operating conditions ................................................ 5

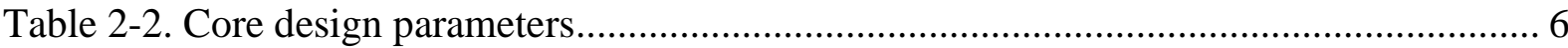

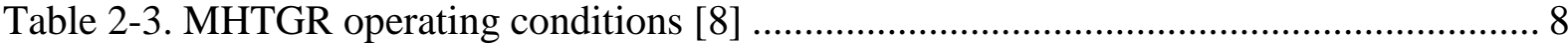

Table 2-4. SAM simulation results at normal operation conditions .................................... 10

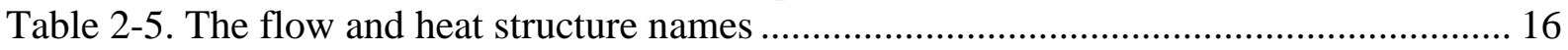

Table 2-6. Compassion of maximum values for reactor transients with normal operating

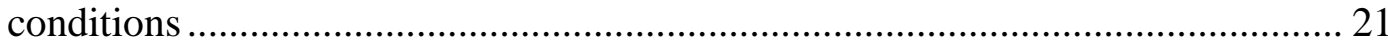

Table 3-1. DTHT benchmark test operating conditions for inlet temperature of $304 \mathrm{~K}$ [3-

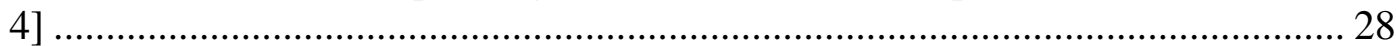

Table 3-2. CFD model description for DTHT [4] ........................................................... 29

Table 4-1. DTHT benchmark test operating conditions for inlet temperature of $304 \mathrm{~K}$........ 35

Table 4-2. Wall heat transfer correlations ....................................................................... 35 


\section{INTRODUCTION}

For safety and licensing purposes, we must analyze the transient response of High Temperature Gas-cooled Reactors (HTGR) to hypothetical accident scenarios such as Loss Of Forced Circulation (LOFC) or Pressurized Conduction Cooldown (PCC). The resulting flow and temperature distribution were complex, as coolant rises from the lower plenum to up through the core and upper plenum (Figure 1-1(ii)). There is a potential for the heat transfer to be degraded during the transition to natural circulation as coolant in the channels may shift from a turbulent to a laminar flow regime. In Figure 1-1(i), the coolant flow direction, i.e. downward flow in the HTGR active core, is shown for normal operating condition.

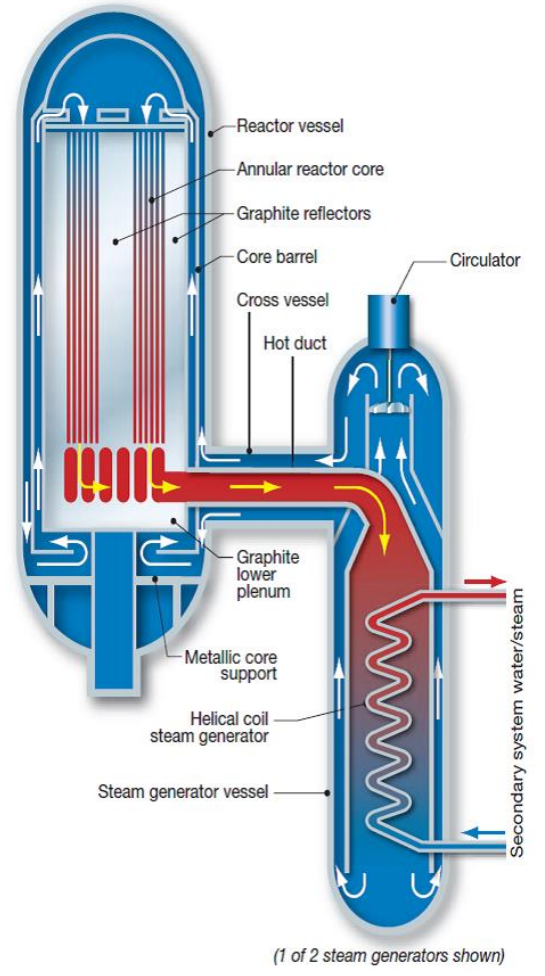

Figure 1-1. HTGR (i) normal operating condition, (ii) natural circulation (yellow arrows) pathways during PCC event [1-2]

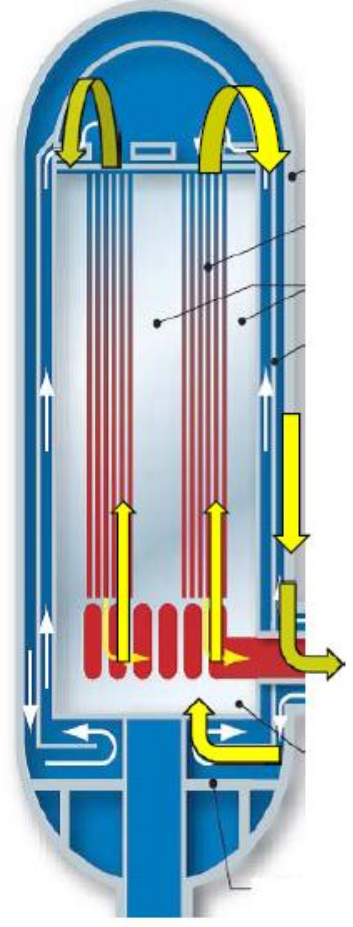

(ii)

Assumptions for the postulated LOFC scenario include: the initiating event leads to a loss-ofoffsite power, reactor scram, and thus loss-of-power to the blower. The scenario quickly progresses from the system's normal operational conditions to a natural circulation condition as the blower coast down. The reactor flow, normally moving downward through the core and into the lower plenum, stagnates and reverses since the driving force is the helium density gradient in the primary heat transport system. Hence the flow occurs upward through the core and forms jets and plumes which leave the top of the core and may move upward to impinge on the ceiling of the upper plenum. Heat transfer within the core moves radially through the prismatic blocks, while some fraction of the core-generated heat is carried upward by the natural circulation flow. The graphite in the core and the core reflectors, nominally cool, begin a prolonged heat-up (the graphite acts as a heat-storage medium) while heat is transferred through the reactor vessel walls to be both transferred from the reactor vessel walls to the Reactor Cavity Cooling System (RCCS) via 
radiation and to the confinement air via convective currents driven by convective heat transfer. The heat transferred to the RCCS is transported to the environment via the RCCS cooling channels which deliver environmental air to the RCCS ducts to pick up heat and to transport the heat energy to the environment. Heat transfer to the medium surrounding the containment structure (soilsince the MHTGR is installed below ground) also assists in removing heat from the containment. To be noted, RCCS behavior is generally very important in LOFC events since the RCCS becomes the only effective means of removing afterheat from the core and vessel.

The core coolant flow distribution during the LOFC is dictated by a number of factors such as; (a) the core power distribution, (b) helium viscous properties, i.e., helium viscosity increases with increasing temperature; hence hot spots have reduced helium cooling for unchanging pressure but increasing temperature conditions-while cool spots have increased helium cooling stemming from lower temperatures relative to the hot spots, and (c) the core bypass fraction. The presence of adequate core cooling will ensure peak fuel temperatures do not approach regulatory upper temperature limits. Factors which are important for ensuring that fuels and structural materials in an operational gas-cooled reactor do not exceed a regulatory limit include:

i. Localized core cooling distributions proportional to the magnitude of localized core power; i.e. if the design is predicated on ensuring adequate cooling is used to assure adequate cooling for "hot" fuel pins then the core fuel bulk temperatures will always be well below the regulatory allowable peak fuel temperature limits.

ii. Prevention or proper accounting for effects that reduce core cooling-such as laminarization - a degraded turbulent heat transfer phenomena.

The gas-cooled reactor designs studied to date generally follow the practice given as item (i) above. However, the level-of-knowledge does not include convincing evidence that phenomena such as laminarization will not occur. For some natural circulation conditions, experiments performed at MIT have demonstrated the presence of laminarization [3] under certain conditions which needs further clarification whether such conditions will occur in a HTGR. For the core, during operational and accident conditions, the core channel flow rates in a prismatic gas-cooled reactor may be laminar, turbulent, or in a transition region. If the flow is turbulent - there is the possibility that laminarization exists. In this work, CFD models were validated with MIT benchmark test [4]. Further, the validated CFD models were used to develop the wall heat transfer correlations due to scarcity of experimental data for laminar flow conditions to guide low order models like SAM, Pronghorn etc.

A further item of interest regarding the core cooling distribution relates to the location and magnitude of high temperature jets exiting the core region. Logically, especially hot jets may be thought to occur in core cooling channels adjacent to markedly "hot" fuel. In our previous work, $1 / 16^{\text {th }}$ scaled Very High Temperature Reactor (VHTR) upper plenum benchmark test was simulated using Nek5000 to study the isothermal jet mixing effects in upper plenum $[2,5]$.

Finally, the bypass flows in a prismatic gas-cooled reactor (GCR) are of concern because they reduce the desired flow rates in the coolant channels and, thereby, can increase outlet gas temperatures and maximum fuel temperatures. In existing literature, bypass flows of 10 to 30 percent of the total flow rate have been estimated [1]. Consequently, it is important to account for bypass flows in reactor thermal gas dynamic analyses. Hence, the bypass flow effects in HTGR should be addressed in the future work. 
In this report, the results can be found in Section 2 for MHTGR primary loop simulations using an advaned system code SAM. 3D CFD models were validated with MIT relaminarization benchmark test in Section 3. Further, the validated CFD models were used to develop the wall heat transfer correlations in Section 4. Finally, the future work was proposed in Section 5. 


\section{Modeling and Simulations of MHTGR Using SAM Code}

\subsection{Background}

An advanced system analysis tool SAM [6,7], is under development at Argonne National Laboratory for advanced non-LWR reactor safety analysis. It aims to provide fast-running, modest-fidelity, whole-plant transient analyses capabilities, which are essential for fast turnaround design scoping and engineering analyses of advanced reactor concepts. SAM aims to be a generic system-level safety analysis tool for advanced non-LWRs. Although previous developments have been focused on single-phase liquid-cooled systems including Liquid-Metal-cooled fast Reactors (LMR), Molten Salt Reactors (MSR), and Fluoride-salt-cooled High-temperature reactor (FHR), code enhancements for high-temperature gas-cooled reactor (HTGR) modeling needs are being pursued recently.

In this work, SAM code was used to model and simulate MHTGR primary loop. The reactor geometry and active core layout are shown in Figures 2-1 and 2-2, respectively. The active core consists of three fuel rings; inner, middle and outer ring [2]. The inner, middle and outer fuel rings represents fuel assemblies of 30, 36 and 36, respectively. Each fuel assembly consists of multiple coolant channels and heat structures such as fuel, graphite and clad. The geometry details and operating conditions are specified in Tables 2-1 and 2-2.

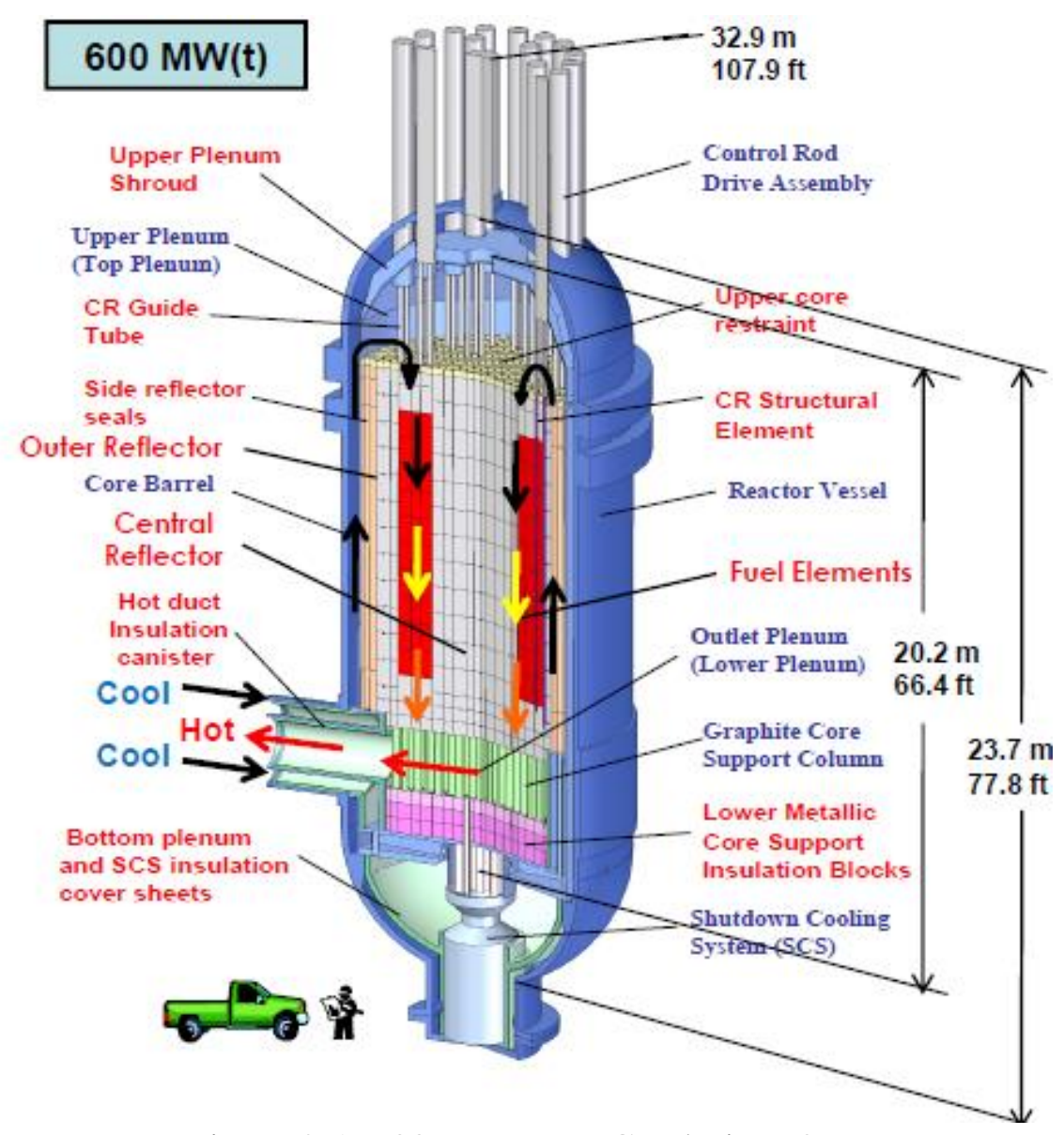

Figure 2-1. 600 MW MHTGR design [8] 


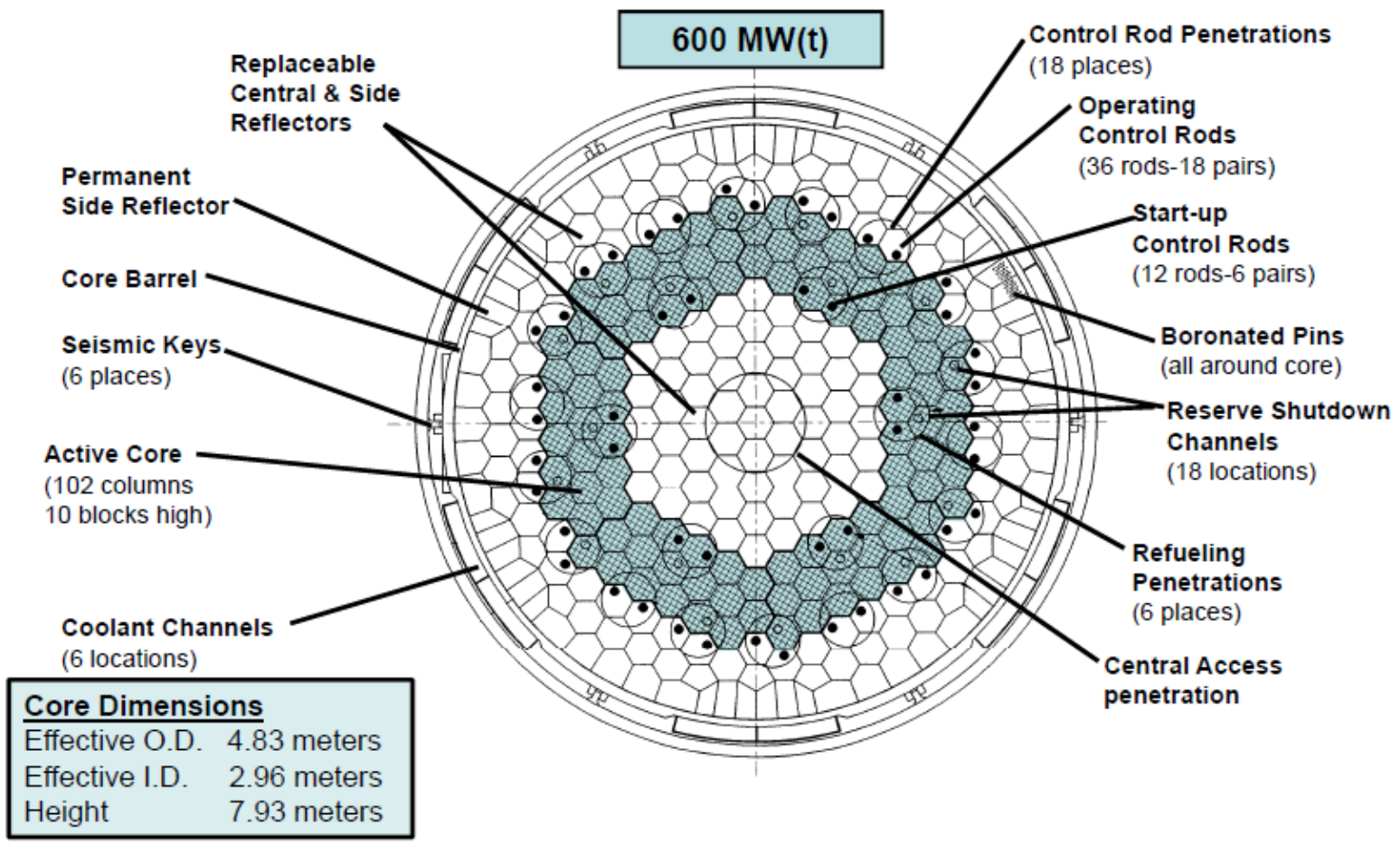

Figure 2-2. Active core layout [8]

Table 2-1. Fluid properties and operating conditions

\begin{tabular}{|c|c|}
\hline Pressure [MPa] & $7.00 \mathrm{E}+06$ \\
Viscosity [Pa s] & $3.31 \mathrm{E}-05$ \\
Inlet core temperature [K] & 623.15 \\
Outlet core temperature [K] & 1023.15 \\
Specific heat @ inlet $[\mathrm{J} / \mathrm{kg}-\mathrm{K}]$ & 5188 \\
Thermal conductivity @inlet [W/m-K] & 0.2619 \\
Density @inlet $\left[\mathrm{kg} / \mathrm{m}^{3}\right]$ & 5.36 \\
Mass flow rate in core $[\mathrm{kg} / \mathrm{s}]$ & 289.128 \\
Mass flow rate per channel $[\mathrm{kg} / \mathrm{s}]$ & 0.0277 \\
Velocity [m/s] & 26.194 \\
Reynolds number & $1.38 \mathrm{E}+05$ \\
Power [MW] & 600 \\
\hline
\end{tabular}


Table 2-2. Core design parameters

\begin{tabular}{|c|c|}
\hline Fuel compact per fuel hole & 0.9333 \\
Fuel holes & 210 \\
No. of rods & 3126 \\
No. of fuel particles [Million] & 17.2 \\
Graphite [kg] & 90 \\
Fuel assembly [kg] & 122 \\
Control channel [inch] & 4 \\
No. of coolant channels & 102 \\
Coolant channel dia. [mm] & 15.875 \\
Triangular pitch between coolant channels [mm] & 32.6 \\
Edges [mm] & 208 \\
Width [mm] & 416 \\
Depth [mm] & 360 \\
No. of fuel assemblies & 102 \\
\hline
\end{tabular}

To adderess the different needs to simulate HTGR under different conditions, i.e., normal operation condition and transient conditions, two approaches had developed to model HTGR reactor core using SAM. These two approaches are (i) unit-cell (also known as single-channel) approach that uses representative geometry to approximate fuel assembly, and (ii) ring model $[9,10]$, in which all reactor core components, including fuel assemblies, inner and outer reflectors, core barrel, and Reactor Pressure Vessel (RPV), were modeled as rings. The unit-cell approach is suitable to model MHTGR core in normal operation condition, as the most important $\mathrm{T} / \mathrm{H}$ characteristic is the conjugate heat transfer between coolant channel and its surrounding graphite moderator and fuels. Such an approach is, however, not sufficient to caputre the core radial heat conduction through fuel assemblies, which is the dominant phenomenon during certain transients, such as the PCC event of interest in this study. For this reason, the ring model has been developed. In the ring model approach, reactor components were modeled as rings, such that we can take advantage of the axial symmetric of core geometry, and two-dimensional RZ (radially and axially) geometry could be used to reduce computational cost during transient simulations. Other primary loop components, such as the lower and upper plenum, heat exchanger and blower, were included and kept the same in all SAM simulations.

\subsection{Unit-Cell (or Lumped Parameter) Model}

In SAM, "PBCoreChannel" component was selected to model both coolant channel and heat structures in the unit-cell core model. It uses one average fuel-block coolant-channel cell to represent the active core. The primary loop geometry consists of upper and lower plenum, coolant channels, heat exchanger and blower configuration as shown in Figure 2-3. To simulate a fuel assembly, the required information for this component includes heat structure thickness, coolant channel hydraulic diameter, total coolant channel cross section area, length of the core, heat surface area density, power distribution and number of fuel rods. Initial and operating conditions are specified in Table 2-3. The axial power distribution is shown in Figure 2-4. 


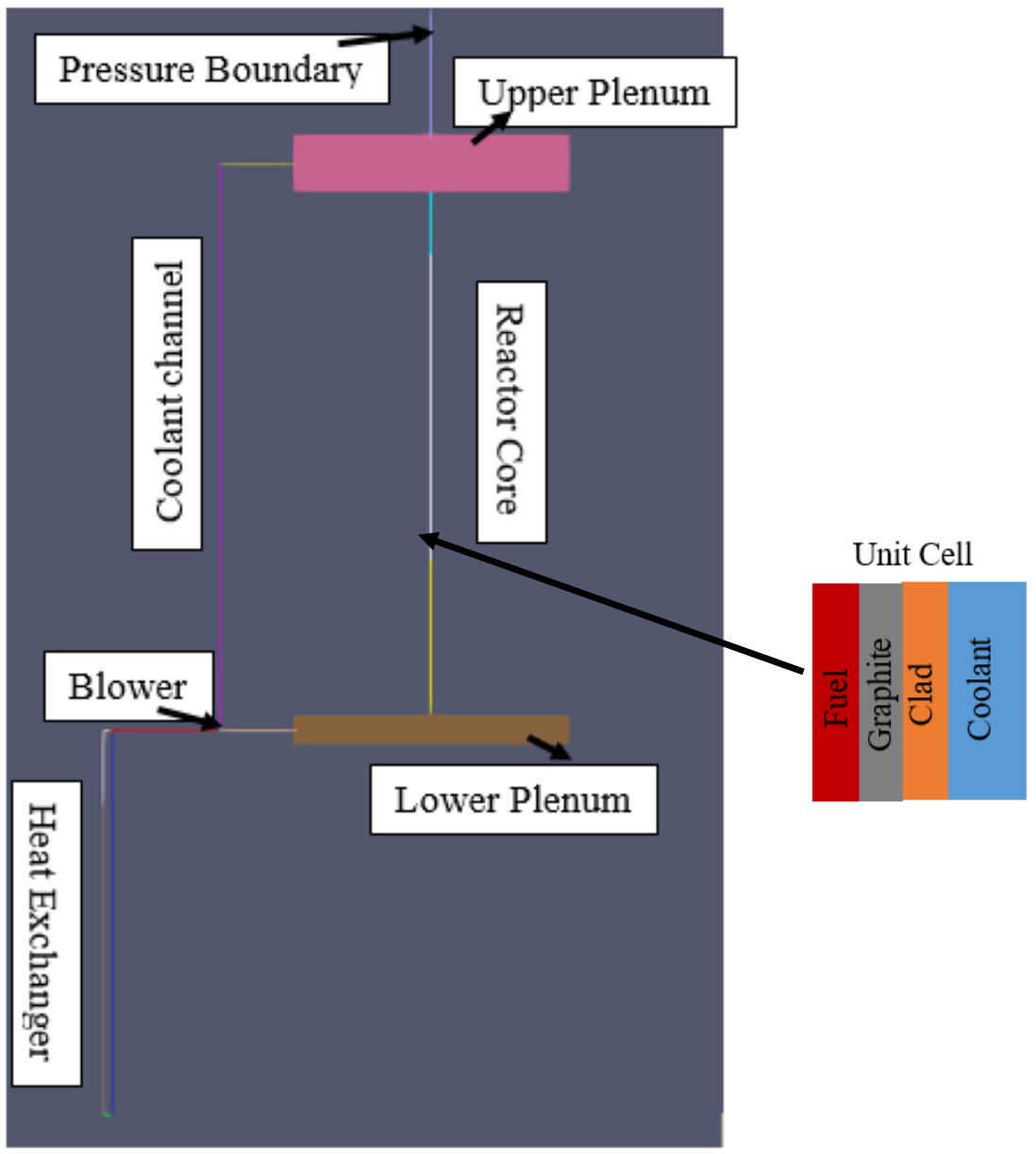

Figure 2-3. MHTGR Primary loop geometry

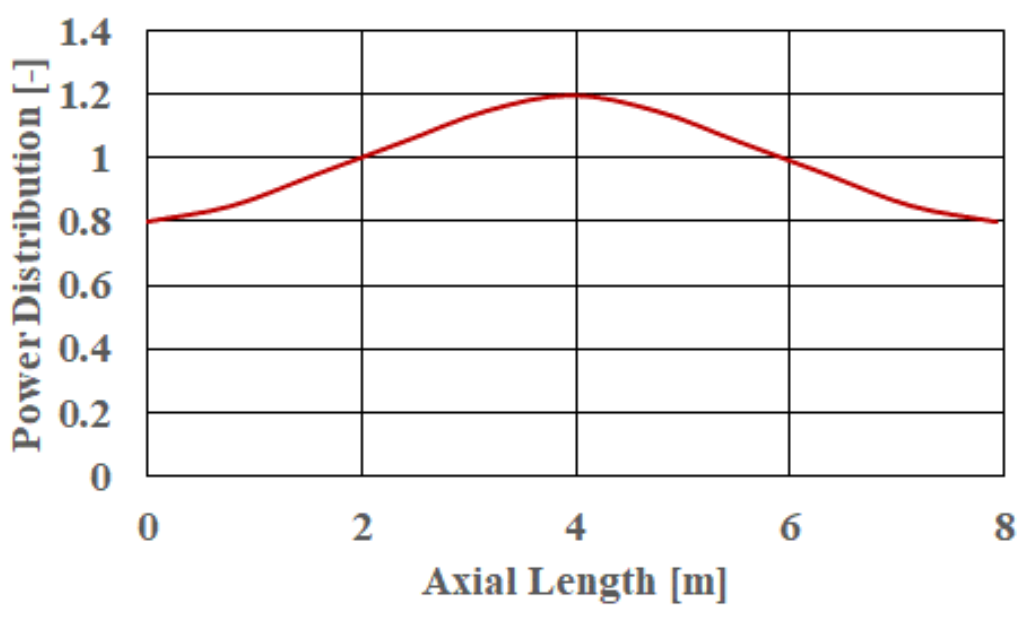

Figure 2-4. Power distribution axial profile for active core 
Table 2-3. MHTGR operating conditions [8]

\begin{tabular}{|c|c|}
\hline Pressure $[\mathrm{MPa}]$ & $7.0 \mathrm{E}+06$ \\
Inlet core temperature $[\mathrm{K}]$ & 623.15 \\
Outlet core temperature $[\mathrm{K}]$ & 1023.15 \\
Mass flow rate in core[kg/s] & 289.12 \\
Total core flow area $\left[\mathrm{m}^{2}\right]$ & 2.059 \\
Fuel thickness $[\mathrm{mm}]$ & 2.065 \\
Graphite thickness $[\mathrm{mm}]$ & 0.465 \\
Clad thickness [mm] & 0.52 \\
No. of fuel rods & 21420 \\
Active core height $[\mathrm{m}]$ & 7.93 \\
Upper support heat structure $[\mathrm{m}]$ & 1.617 \\
Lower support heat structure $[\mathrm{m}]$ & 4.04 \\
Heated surface area density $[1 / \mathrm{m}]$ & 199.3 \\
Mass flow rate per channel $[\mathrm{kg} / \mathrm{s}]$ & 0.02779 \\
Velocity $[\mathrm{m} / \mathrm{s}]$ & 26.194 \\
Reynolds number & $1.38 \mathrm{E}+05$ \\
Power $[\mathrm{MW}]$ & 600 \\
\hline
\end{tabular}

\subsubsection{Results for Normal Operating Conditions}

The MHTGR simulation results for normal operating conditions at the steady state were obtained using SAM's transient solver. Figure 2-5 shows SAM simulation results of coolant temperature and velocity in the primary loop. During normal operation, coolant flow is downward in reactor, and the coolant temperature increases from top to botoom as it is heated in the reactor core, Figure 2-5(i). The magnitude of coolant velocity also increases, Figure 2-5(ii), as coolant density drops as a results of being heated. Similarly, the temperature increase was observed in heat structures towards the lower plenum (figure 2-6). The hot coolant from the lower plenum was cooled in heat exchanger before it sends to blower. The blower drives the riser flow in a RPV coolant channel which was located between reactor pressure vessel and core barrel and it was connected with upper plenum. 


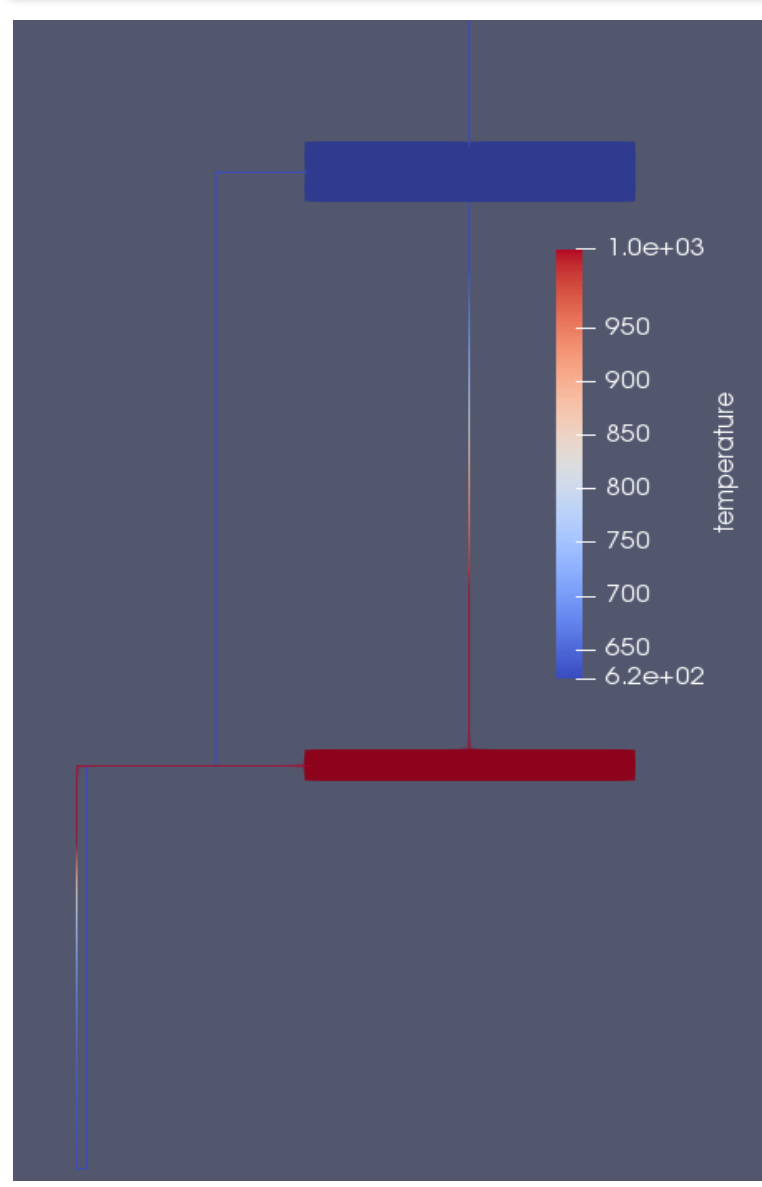

(i)

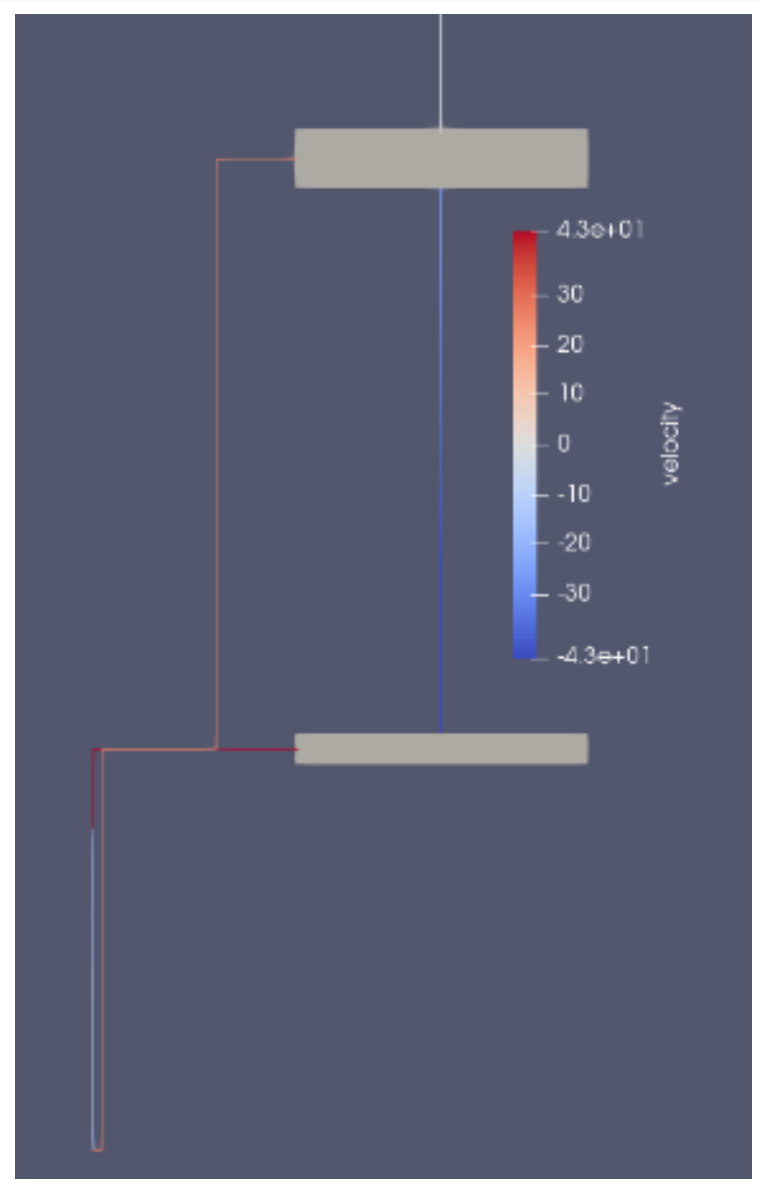

(ii)

Figure 2-5. Fluid fields for (i) temperature and (ii) velocity

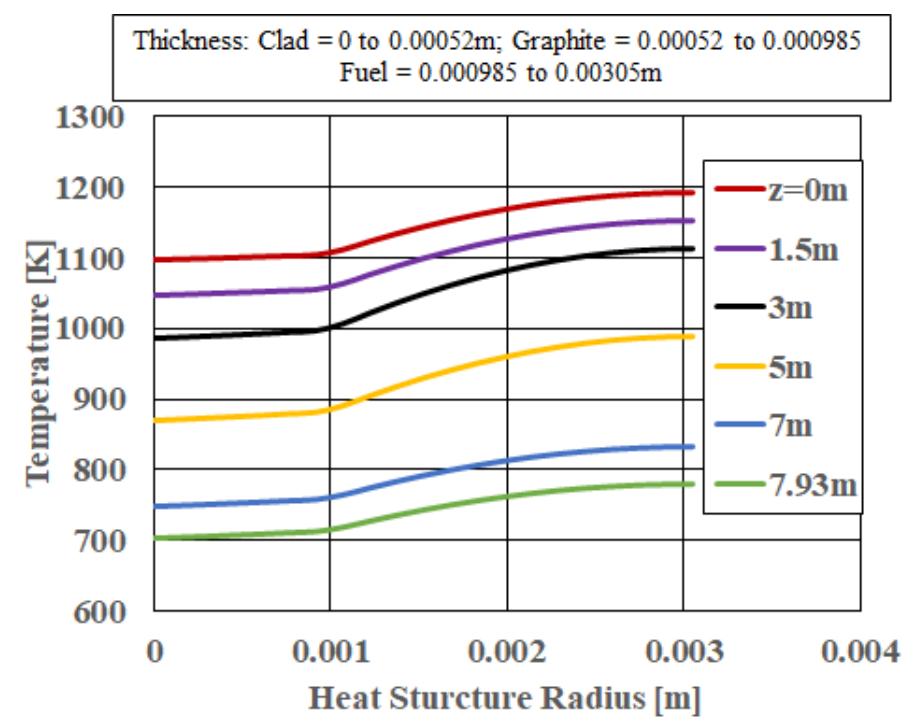

Figure 2-6. Solid temperature radial distribution at various axial location in a primary loop 
In Figure 2-7, the temperature and velocities were shown for the coolant channel along the axial direction of the active core. The significant increase of coolant velocity and temperature were observed towards bottom of the reactor core, as expected. It should be noted that the increased velocity was mainly due to helium density drop with an increase of coolant temperature, towards bottom of the active core.

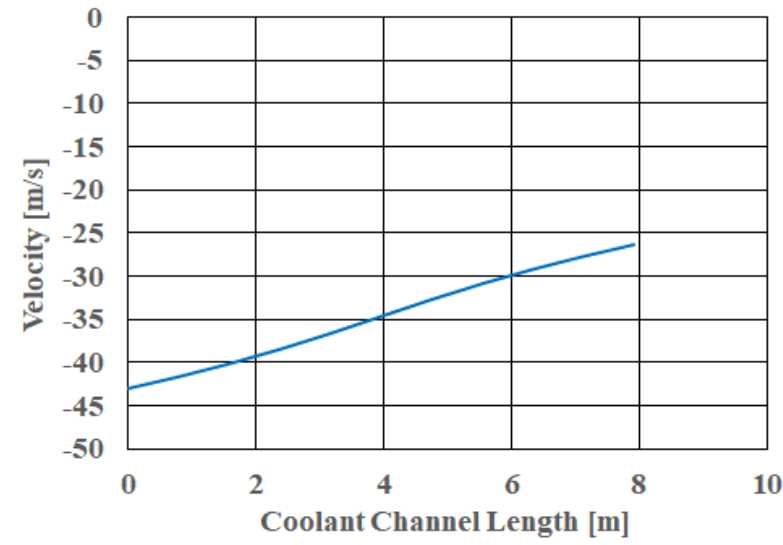

(i)

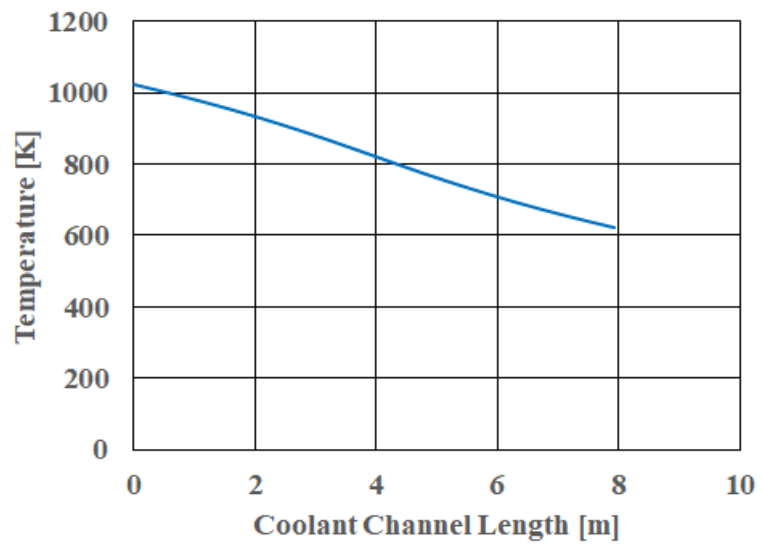

(ii)

Figure 2-7. Fluid profile along the axial length of the active core (i) Velocity and (ii) Temperature

As seen in Table 2-4, the SAM code simulations results for normal operation conditions were almost identical to the MHTGR design conditions, which indicates that a good reference model has been developed. It is also noted that the maximum temperatures for both coolant and heat structures were well below the specified design limits.

From Figure 2-8, the upper and lower plenum temperature were converged to steady state. Similarly, the predicted maximum temperatures for fuel, clad, graphite and coolant reached a steady state under normal operating conditions.

Table 2-4. SAM simulation results at normal operation conditions

\begin{tabular}{|l|c|c|}
\hline \multicolumn{1}{|c|}{ Parameters } & $\begin{array}{c}\text { Simulation } \\
\text { results }\end{array}$ & $\begin{array}{c}\text { Design } \\
\text { conditions }\end{array}$ \\
\hline Inlet core temperature [K] & 623.14 & 623.15 \\
Outlet core temperature [K] & 1023.26 & 1023.15 \\
Pump flow rate [kg/s] & 289.05 & 289.1 \\
Upper plenum temperature [K] & 623.14 & 623.15 \\
Lower plenum temperature [K] & 1023.26 & 1023.15 \\
Heat exchanger primary outlet temperature [K] & 623.14 & 623.15 \\
Peak Fuel temperature [K] & 1191 & - \\
Peak Clad temperature [K] & 1101.5 & - \\
Peak Graphite temperature [K] & 1105.3 & - \\
\hline
\end{tabular}




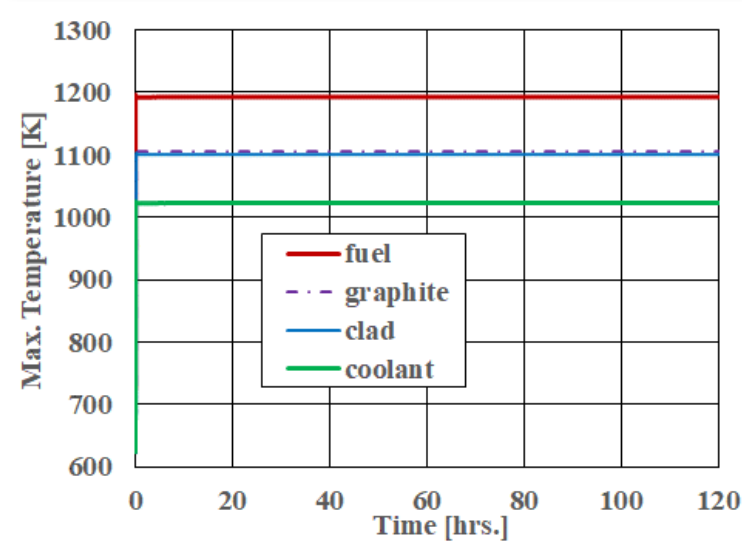

(i)

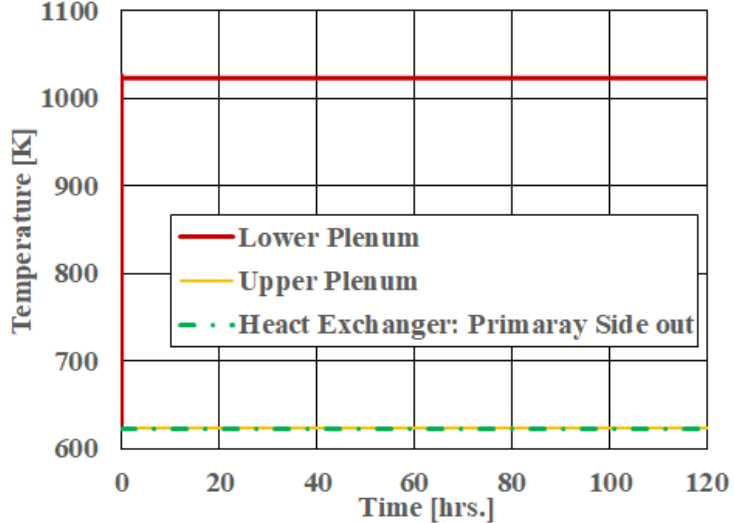

(ii)

Figure 2-8. Maximum temperatures vs. time

\subsubsection{Simulation Results for Controlled Reactor Transients}

To examine the code capabilities and performance, the power operation transient simulations were performed with specified time histories of power, pump head and heat exchanger secondary coolant mass flow rates, as shown in Figure 2-9.

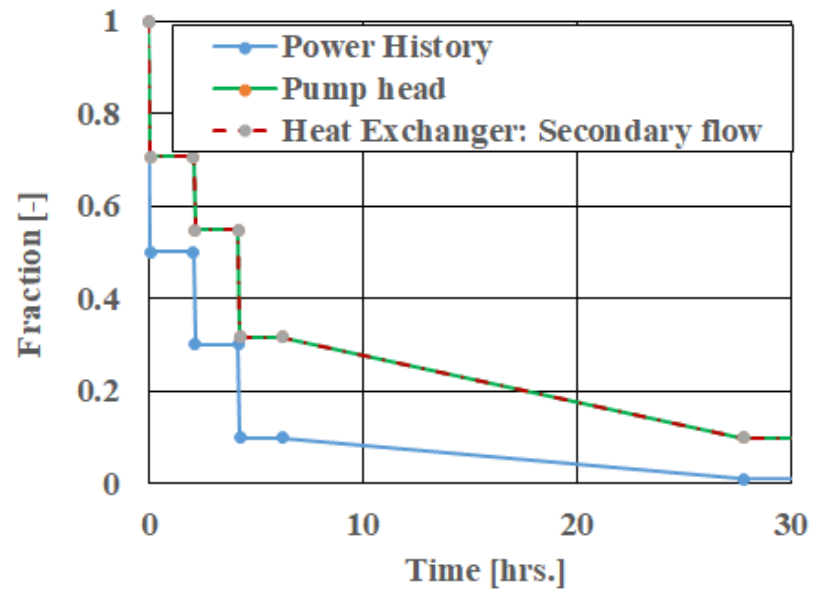

Figure 2-9. Controlled reactor transient profiles for power, pump head and heat exchanger secondary flow

SAM simulation results of power transients were shown in Figure 2-10. The maximum temperature drop was observed up to $\sim 0.1 \mathrm{hr}$ due to the much-reduced power level but relative higher flow rates in both the primary loop and the secondary side of the heat exchanger. The moderate increase was observed between $\sim 0.1$ and $\sim 4.2 \mathrm{hrs}$ where the increase of power to flow ratio during the time period. Furthermore, the significant increase was observed from $\sim 4.2 \mathrm{hrs}$ onwards. The temperature jump at $4.2 \mathrm{hrs}$ was mainly due to increased ratio of reactor power to flow ratio, and the reactor power to heat exchanger removal ratio (Figure 2-10(iv)). The velocity drop (Figure 2-10(iii)) is in line with the specified profiles in Figure 2-9. 


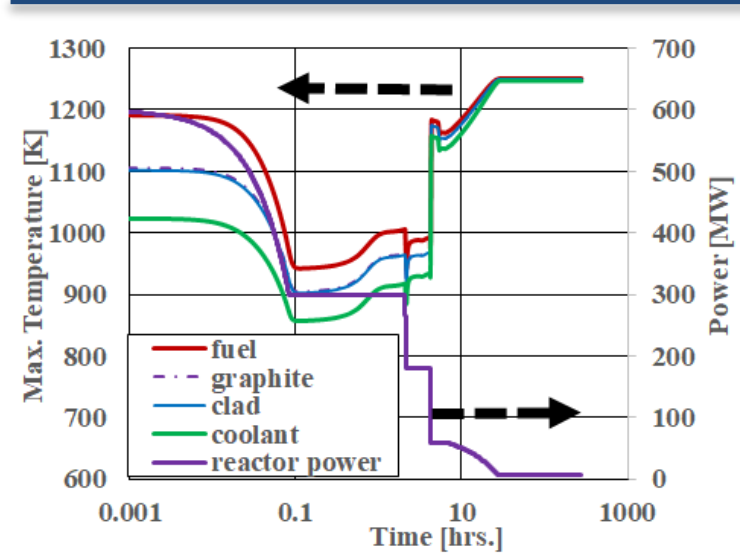

(i)

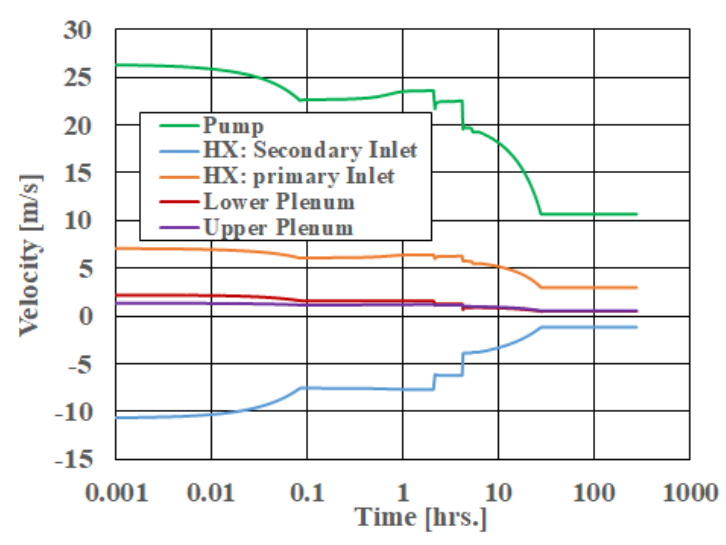

(iii)

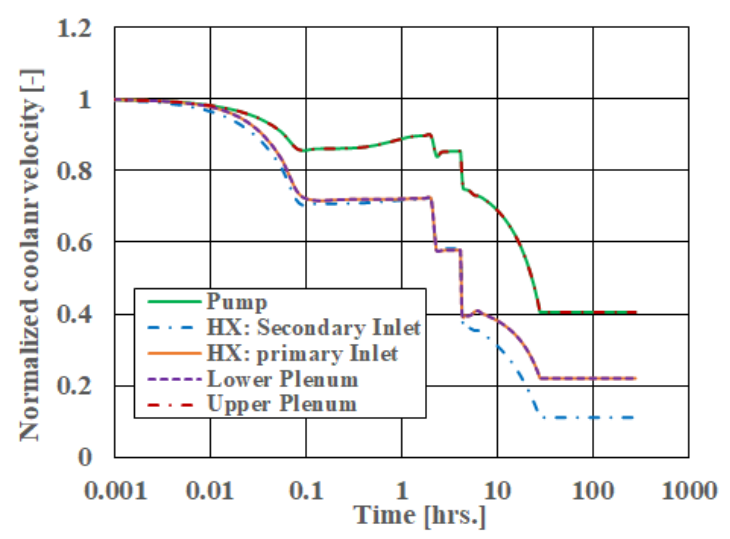

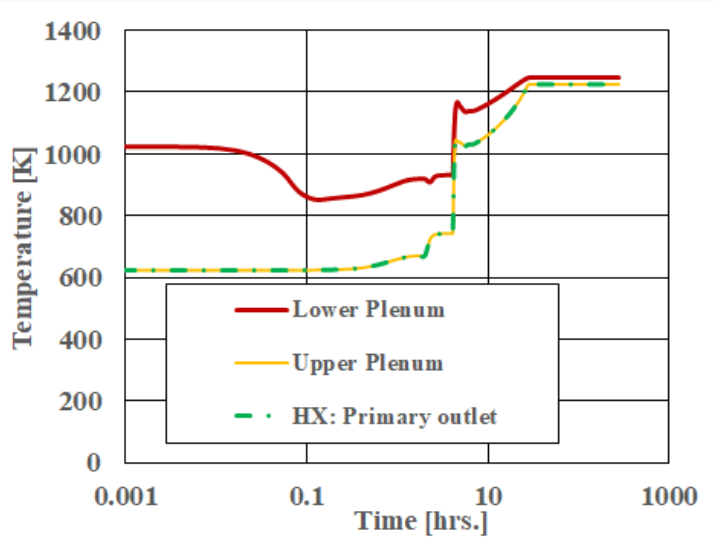

(ii)

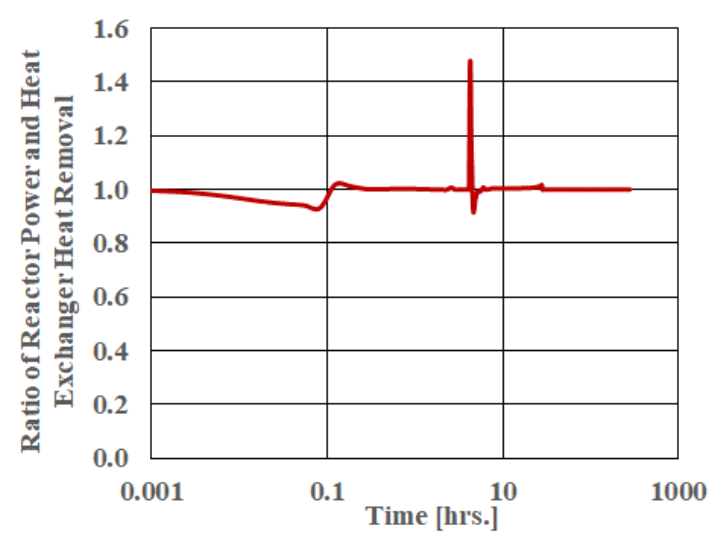

(iv)

(

Figure 2-10. Time profiles for (i) maximum temperatures, (ii) coolant temperature, (iii) coolant velocity, (iv) ratio of reactor power to heat exchanger removal and (v) normalized flow or velocity 


\subsection{SAM Ring Model}

To capture the radial heat conduction in reactor core, detailed MHTGR model was developed in SAM using a ring approach based on a specified coolant channel pitch of fuel assembly, similar to the concept used in [9].

A simplified ring model was first developed, in which each fuel ring (inner, middle, and outer) is modeled as one ring in the SAM model. In this simplified ring model, the each fuel assembly represents 1 coolant channels and 2 heat structures (Figure 2-12(i)). The heat structure ring thickness was calculated based on the material volume to represent actual geometry dimensions as similar to detailed ring model. Hence, the active core (fuel assemblies) was simulated with 9 circular rings where 6 rings for homogenized fuel heat structure and 3 rings for gas coolant.

It was quickly found that the simplified ring model did not produce correct solid temperatures, which is too high as the thickness of heat structures are too large. A detailed ring model is then developed, as depicted in Figures 2-11 and 2-12(ii). In this model, each ring of fuel assemblies is represented by 11 coolant channels and 22 heat structures in order to conserve not only the solid structure volumes but also their representative thicknesses. The each coolant channel was located between two heat structure rings. The heat structure ring thickness was calculated based on the material volume to represent actual geometry dimensions. Hence, the active core (fuel assemblies) was simulated with 99 circular rings where 66 rings for homogenized fuel heat structure and 33 rings for gas coolant. Under this configuration, each coolant channel communicates with its two adjacents heat structures to simulate the conjugate heat transfer. Without introducing additional heat transfer modeling mechanism, each ring is isolated from all other rings, and therefore radial heat conduction in reactor solid strucutres cannot be captured. To overcome this, heat structure surfaces were connected with its adjacents heat structure surfaces using gap heat transfer mechnism provided in SAM. In this work, the gap heat transfer coefficient was assumed to be very large, i.e., $10^{7}$, to avoid temperature discontinuities cross heat structure surfaces.

Besides fule rings, six additional rings were included to represent inner reflector, outer reflector, core barrel, Reactor Pressure Vessel (RPV), RPV coolant channel, and Reactive Cavity Cooling System (RCCS). The radiation heat transfer between reactor pressure vessel and RCCS is also included in the SAM model, and from RCCS, the heat was rejected to ambient air with a provided convective heat transfer coefficient of $19.74 \mathrm{~W} / \mathrm{m}^{2}-\mathrm{K}$.

In SAM, the coolant channels and the heat structures were modeled with 1-D and 2-D components, respectively. In the reactor core, power distribution profile is specified (Figures 2-4 and 2-20). In SAM model, homogenized assumption was considered for fuel ring heat structures. The geometry details and operating conditions are specified in Tables 2-1 and 2-2. The flow and heat structures names were defined in Table 2-5. To be noted, each ring outer radius and its thickness were provided in Appendix (Table A-1). The heated surface area density was calculated based on the radius of the heat structure. 


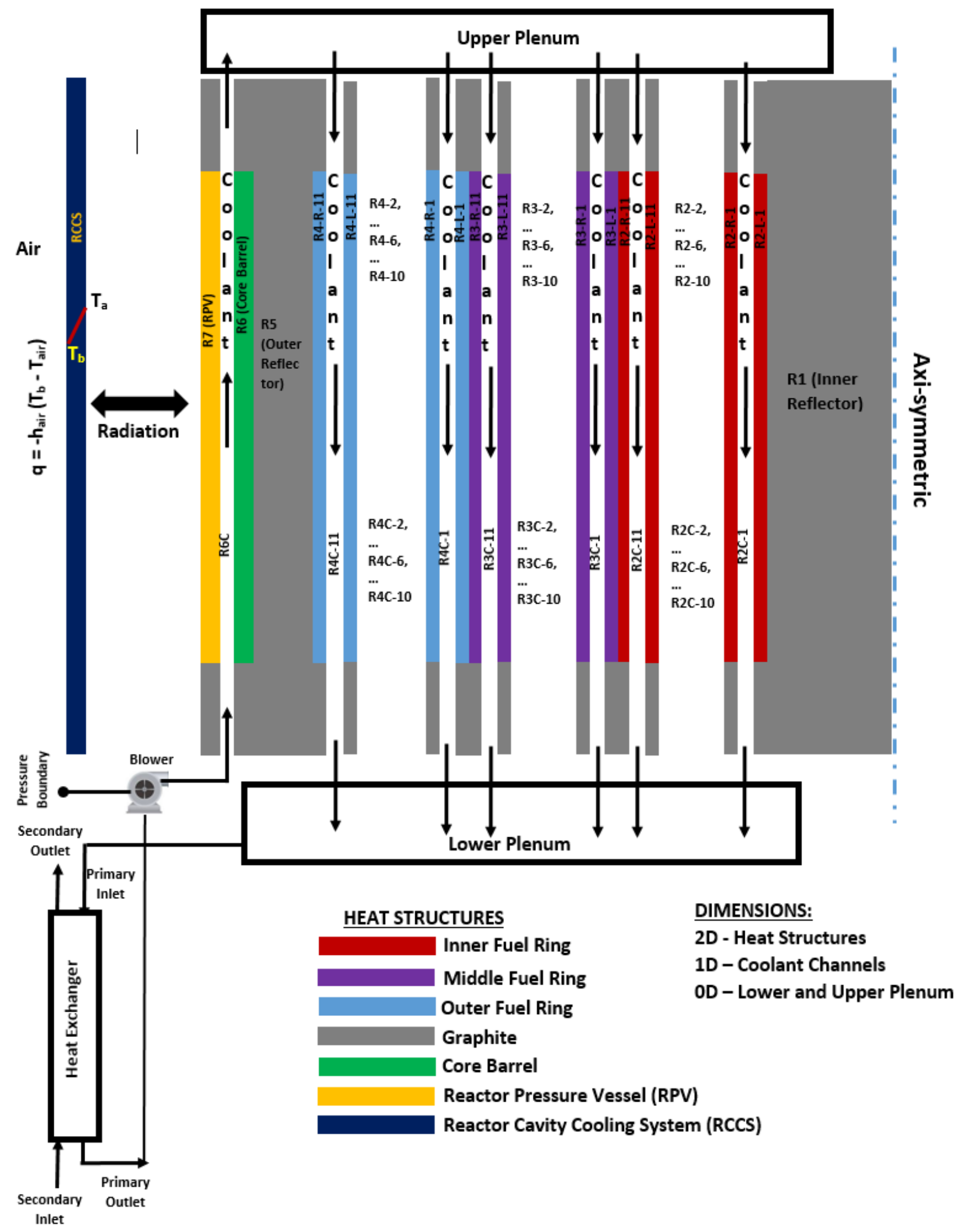

Figure 2-11. SAM model for primary loop (detailed ring model) 
In Figure 2-11, the SAM detailed ring model includes the following procedures:

- Heat structure thickness was based on material volume (reflectors, fuel rings, etc.)

- Number of rings were chosen based on coolant channel pitch of fuel assembly

- Each fuel ring consists of 11 coolant channels and 22 heat structures

- Each coolant channel connected with two identical volume of heat structures

- Gap-heat transfer coefficient was implemented to connect thermal boundary of two different heat structures and also both heat structure and coolant channel

- RCCS was modeled with the specified ambient temperature and convective air heattransfer coefficient

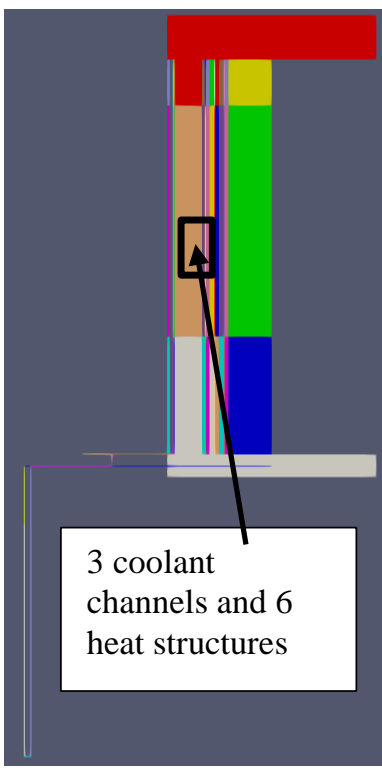

(i)

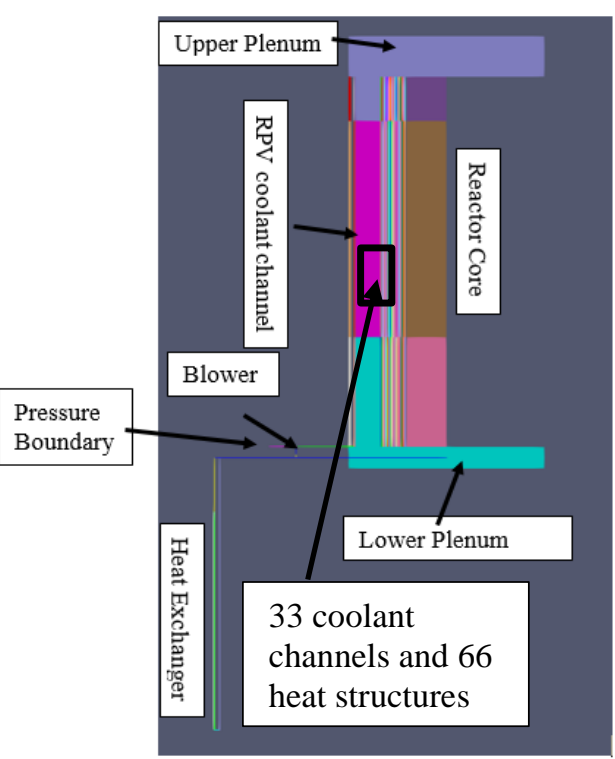

(ii)

Figure 2-12. MHTGR primary loop simulations in paraview; (i) Simplified ring model and (ii) Detailed ring model

The SAM simulations were performed for specified axial power distribution profile (Figure 24). The MHTGR primary loop simulations were performed for normal operating conditions to compare both simplified and detailed ring models. On the other hand, the reactor transient simulations were performed for PCC event using detailed ring model. 
Table 2-5. The flow and heat structure names

\begin{tabular}{|c|c|}
\hline R-1 & Inner reflector \\
R-2-L(11) & Inner fuel ring left structure \\
R2-Channel (11) & Inner fuel ring fuel ring coolant channel \\
R-2-R (11) & Inner fuel ring right structure \\
R-3-L (11) & Middle fuel ring left structure \\
R3-Channel(11) & Middle fuel ring fuel ring coolant channel \\
R-3-R(11) & Middle fuel ring right structure \\
R-4-L(11) & Outer fuel ring left structure \\
R4-Channel(11) & Outer fuel ring Fuel ring coolant channel \\
R-4-R(11) & Outer fuel ring right structure \\
R-5 & Outer reflector \\
R-6 (core barrel) & Core barrel \\
R-6C (coolant) & Coolant channel \\
R-7 (RPV) & Rector pressure vessel \\
RCCS & Reactor cavity cooling system \\
\hline
\end{tabular}

\subsubsection{Results for Normal Operating Conditions}

Figure 2-13 shows the simulation results of reactor core temperatures under normal operation conditions. In simplified ring model (Figure 2-13(i)), the solid temperature in fuel rings were over predicted mainly due to higher thickness of heat structure as discussed previously. On the other hand, the detailed ring model results were reasonable. Henceforth, only detailed ring model results were presented due to its accurate representation of the fuel assemblies than in the simplified ring model.

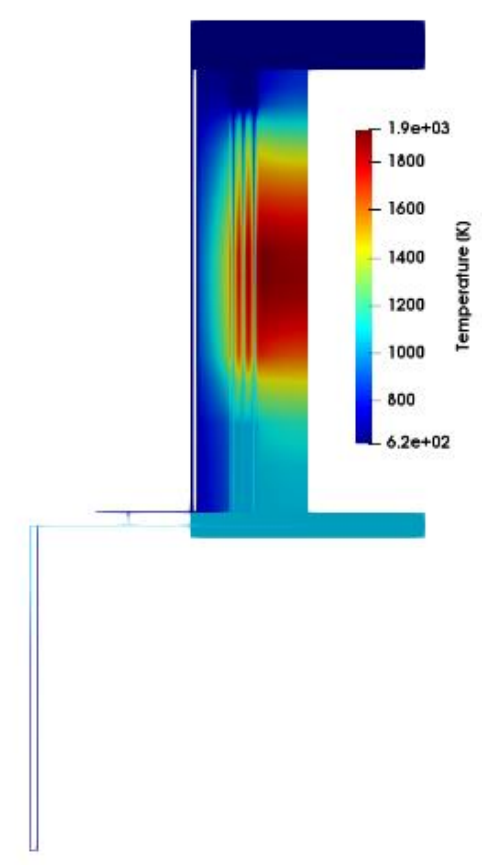

(i)

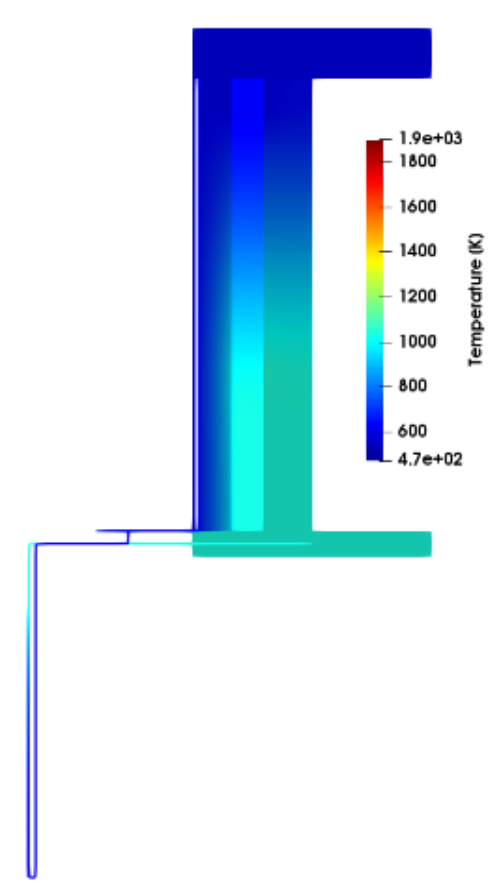

(ii)

Figure 2-13. SAM model temperatures, (i) simplified ring and (iii) detailed ring 
In Figures 2-14 and 2-16, the increase of coolant and solid temperatures in the bottom of the reactor were mainly due to the forced circulation flow from upper to lower plenum. Similarly, the temperature increase was observed in heat structures towards the lower plenum (Figure 2-15). The hot coolant from the lower plenum was cooled in a heat exchanger before it sends to blower. The blower drives the flow towards an upper plenum via RPV coolant channel which was located between reactor pressure vessel and core barrel. Similarly, the velocities increase was observed in coolant channels towards the lower plenum due to density drop. These results were similar to those using the unit-cell approach (see section 2.2.1).

In Figure 2-16, the coolant temperature and velocities were shown for one of the coolant channels from out of 11 from each fuel assembly. To be noted, the results were shown for external coolant channel in each fuel ring. The velocity and temperature increase were observed towards the bottom of active core as expected. In an RPV coolant channel, the change of temperatures and velocities were minimal (R6_C).

In Figure 2-17, the change in solid temperatures were minimal in inner reflector and fuel rings from 0 to $2.41 \mathrm{~m}$. The significant temperature drop was observed in outer reflector, core barrel and reactor pressure vessel including RCCS walls.

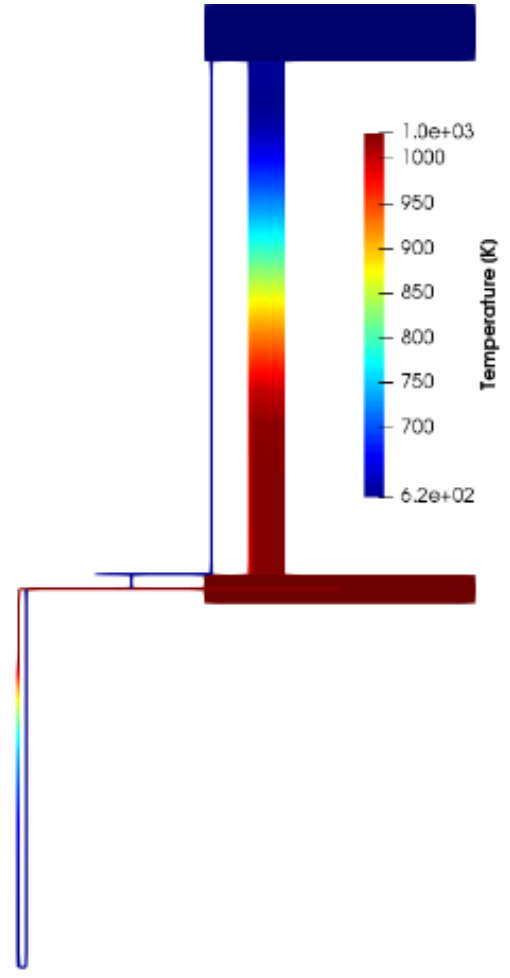

(i)

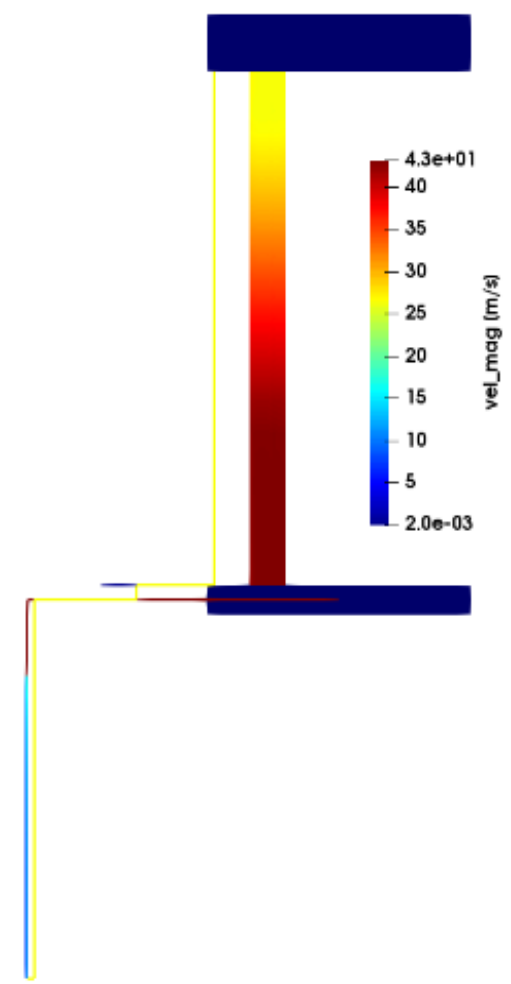

(ii)

Figure 2-14. Coolant fields for (i) Temperature and (ii) Velocity magnitude 


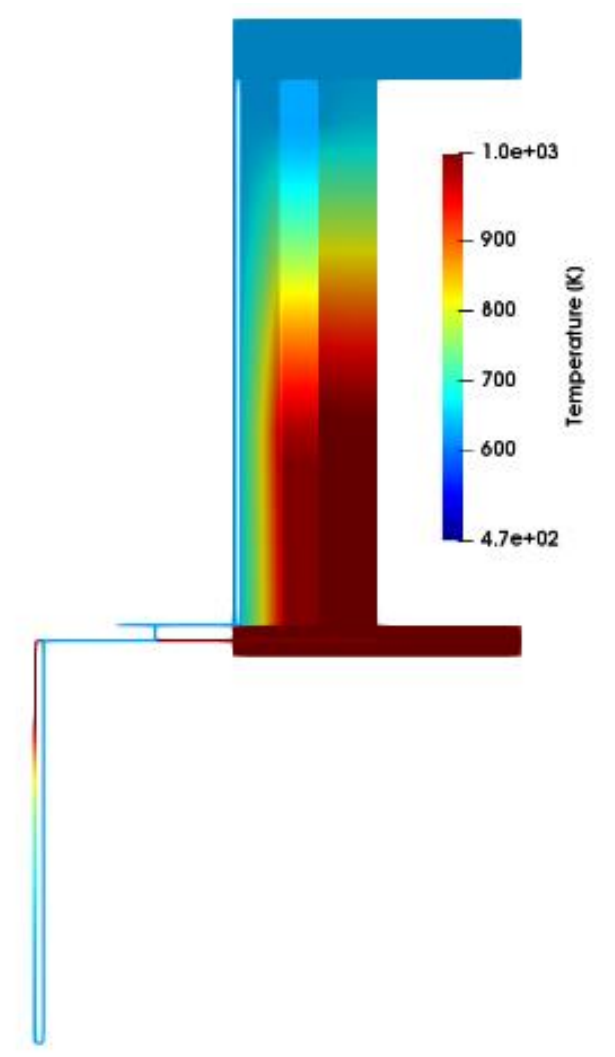

Figure 2-15. Fluid and solid temperature distribution

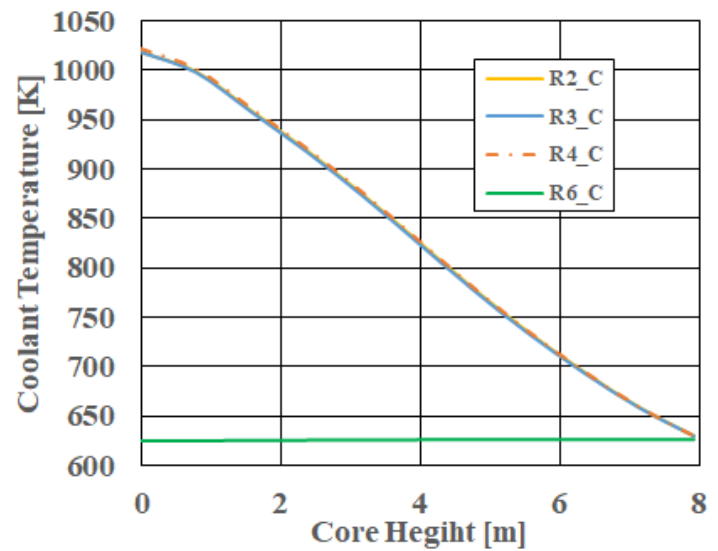

(i)

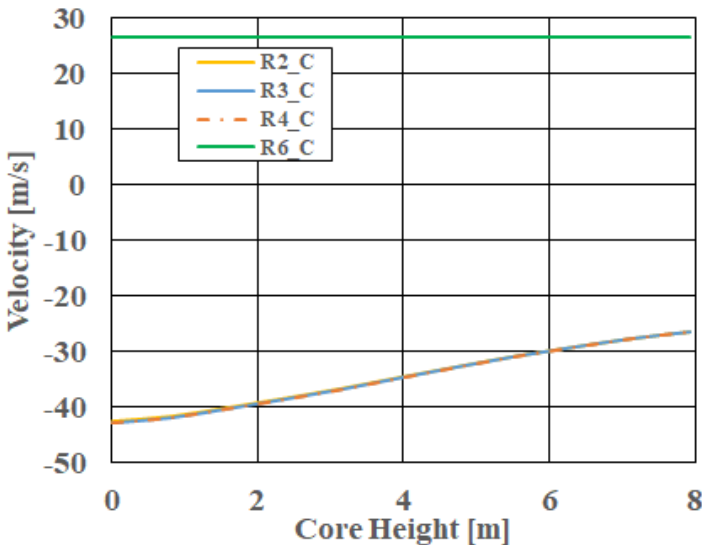

(ii)

Figure 2-16. Active core coolant (i) Temperature and (ii) Velocity 


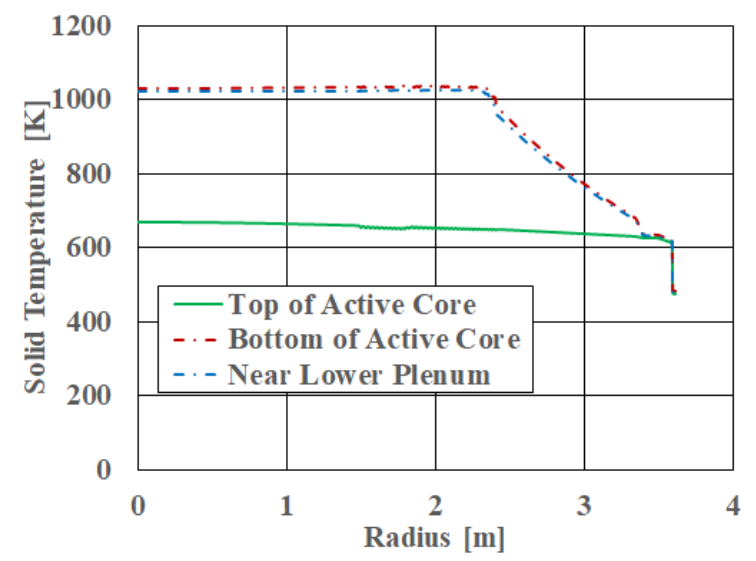

Figure 2-17. Heat structure temperature across radial direction

From Figure 2-18, the upper and lower plenum temperature were converged to steady state. The predicted blower velocities were identical under normal operating conditions with an increase of time. From Figure 2-19, the heat removal through the RCCS was approximately $1.05 \mathrm{MW}$ under normal operating conditions. To be noted, the RCCS was modeled based on radiation heat transfer between RPV and RCCS heat structures. In RCCS, the heat was rejected to ambient air with a provided convective heat transfer coefficient of $19.74 \mathrm{~W} / \mathrm{m}^{2}-\mathrm{K}$.

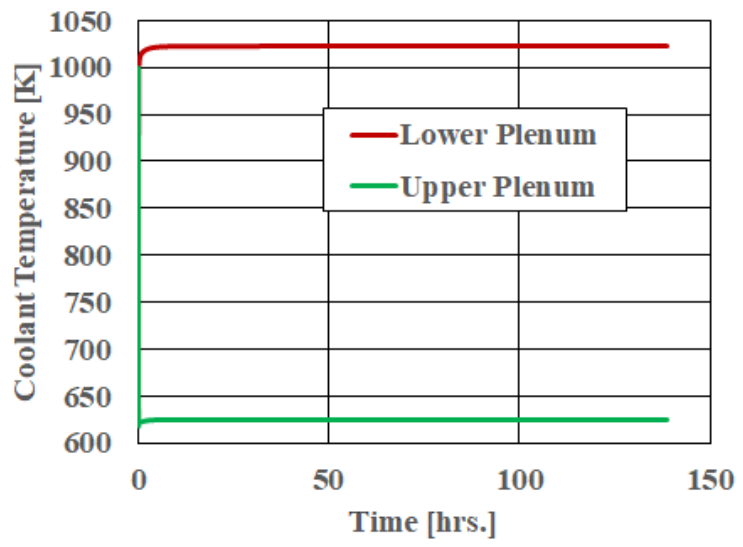

(i)

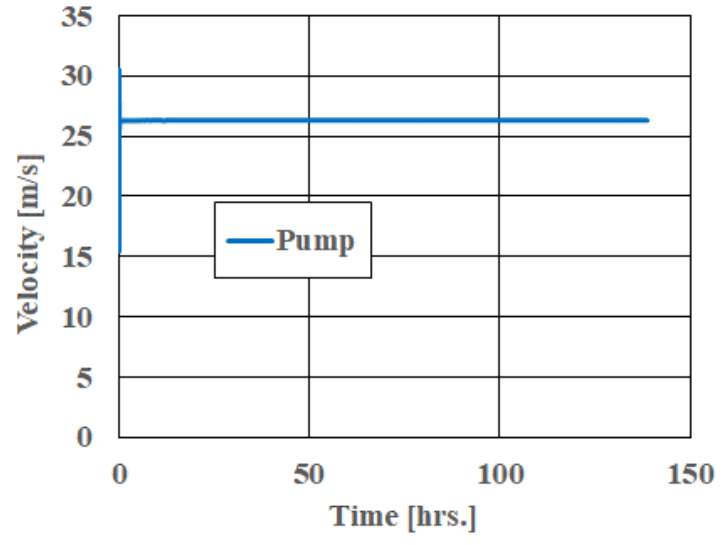

(ii)

Figure 2-18. Maximum values for coolant (i) Temperature and (ii) Velocity 


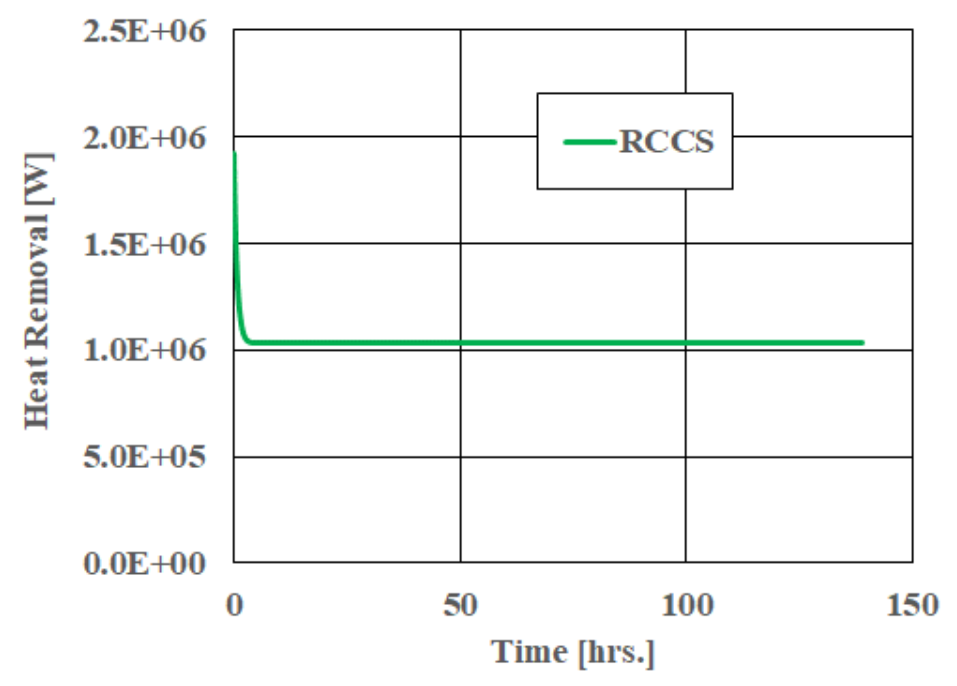

Figure 2-19. RCCS heat removal

\subsubsection{PCC Transient Simulation Results}

In this section, simulations were performed for PCC accident scenario in a reference MHTGR design. The converged results from normal operating conditions were used to run reactor transients with a specified power history profile (Figure 2-20). To be noted, both heat exchanger and blower performance were assumed complete failures (zero pump head and zero heat removal) to study the reactor performance during PCC event.

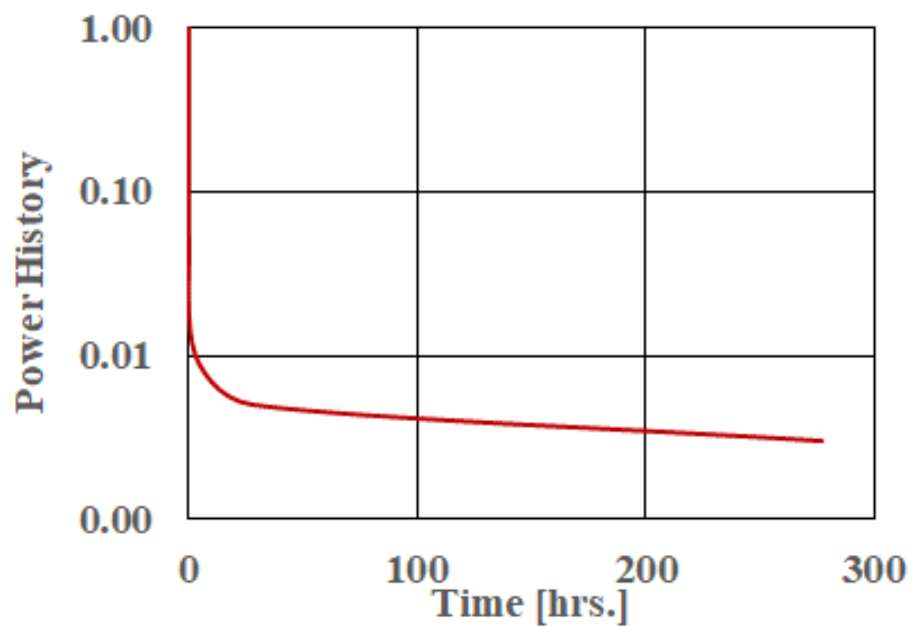

Figure 2-20. Power History for accident scenario [11]

From Figure 2-21, the significant temperature increase was observed in fuel rings, which were within the designed limits. To be noted, the maximum temperature plot was shown only for outermost heat structure from each fuel ring (inner, middle and outer). The details of the maximum temperatures within the reactor were shown in Table 2-6. The reactor core temperatures significantly increased within five hrs of reactor shut down. On the other hand, the moderate 
increase of heat structure temperatures were observed for outer reflector, core barrel, RPV and RCCS.

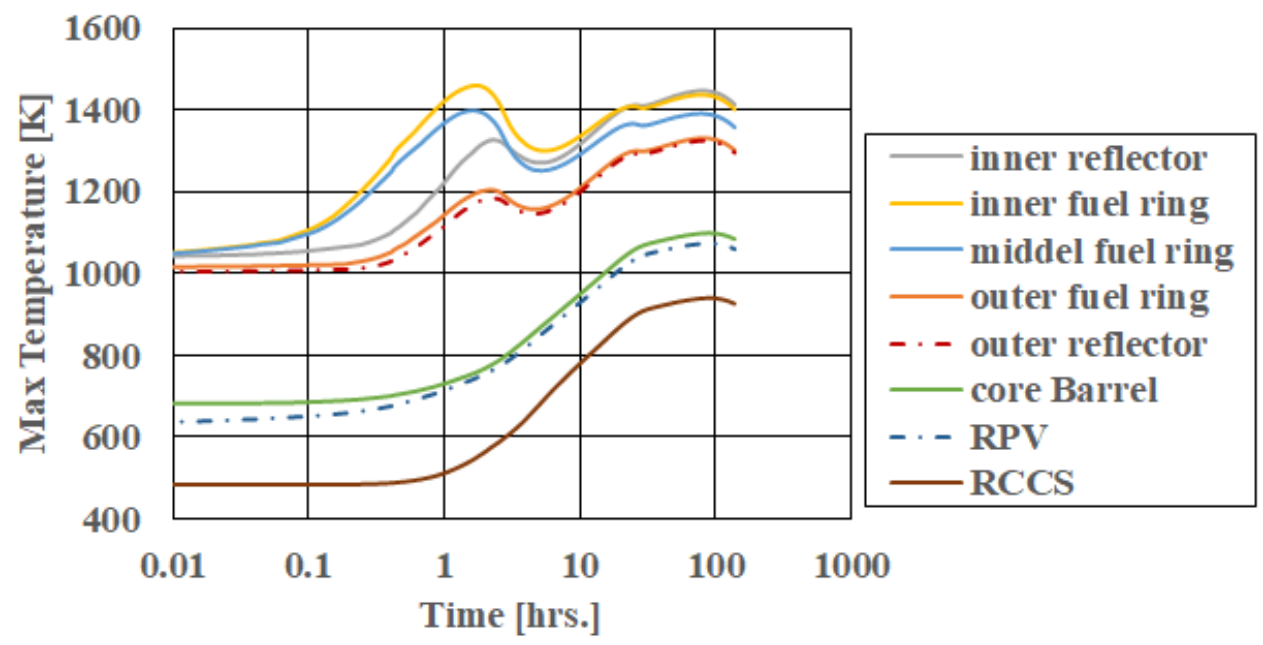

Figure 2-21. Heat structures maximum temperatures

Table 2-6. Compassion of maximum values for reactor transients with normal operating conditions

\begin{tabular}{|l|l|l|}
\hline \multicolumn{1}{|c|}{ Parameter } & Normal & PCC \\
\hline Inner reflector [K] & 1043.22 & 1446 \\
Inner fuel ring [K] & 1042.3 & 1459 \\
Middle fuel ring [K] & 1038.8 & 1397 \\
Outer fuel ring [K] & 982.9 & 1390 \\
Outer reflector [K] & 981.47 & 1292 \\
Core barrel [K] & 678.8 & 1098 \\
RPV [K] & 633.5 & 1073 \\
RCCS [K] & 482.9 & 939 \\
RCCS heat removal [MW] & 1.048 & 3.15 \\
\hline
\end{tabular}

In upper plenum, the coolant temperature increase was observed with an increase of time due to loss of forced circulation flow (Figure 2-22(i)). In contrast, the coolant temperature in lower plenum decreased right after the transient started $(t=0 \mathrm{Sec}$ ). In Figure 2-22(ii) also shows the coolant velocities for pump and heat exchanger. The natural circulation flow was observed due to Buoyancy or density driven flow (Figure 2-22(ii), Figures 2-23(i,ii,iv)). It also justifies that the hot flow rises and mix with cold flow due to density gradients in Buoyancy driven flow.

The flow direction was changed from downward to upward in the reactor core due to loss of forced circulation flow. However, inside the reactor, outer fuel ring shown downward flow due to lower temperatures (Figure 2-23) compared to inner and middle ring (Figure 2-24). Hence, the internal (parallel channel) flow circulation was established in the reactor core.

In Figure 2-24(i-iii), the coolant temperature profiles were shown for one of the coolant channels from inner, middle and outer fuel rings. These coolant channels were considered from 
outermost channel from each fuel ring. Also, the bypass (RPV) coolant channel was shown in Figure 2-24(iv). At top of the active core, the increase of temperatures was due to natural circulation flow, as discussed above (Figure 2-21). Moreover, the temperature magnitudes dropped towards the outer fuel rings.

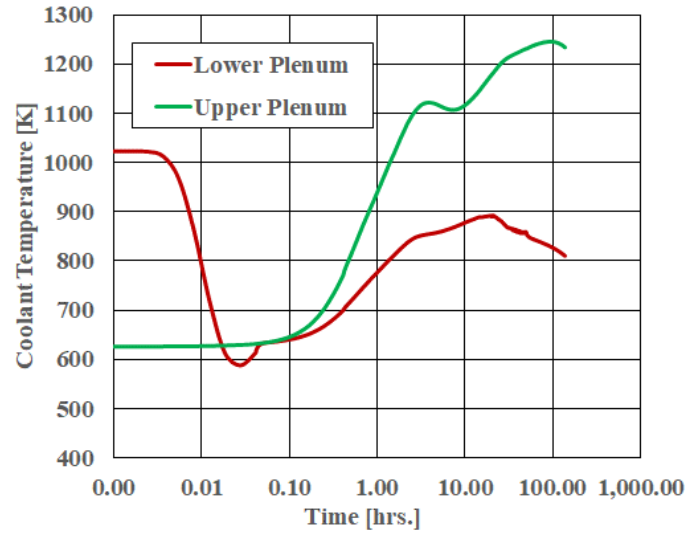

(i)

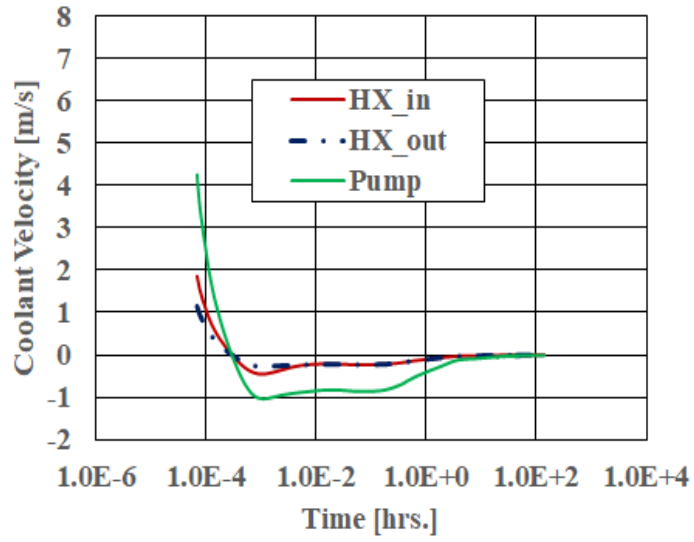

(ii)

Figure 2-22. Coolant maximum values for (i) Temperature and (ii) Velocity

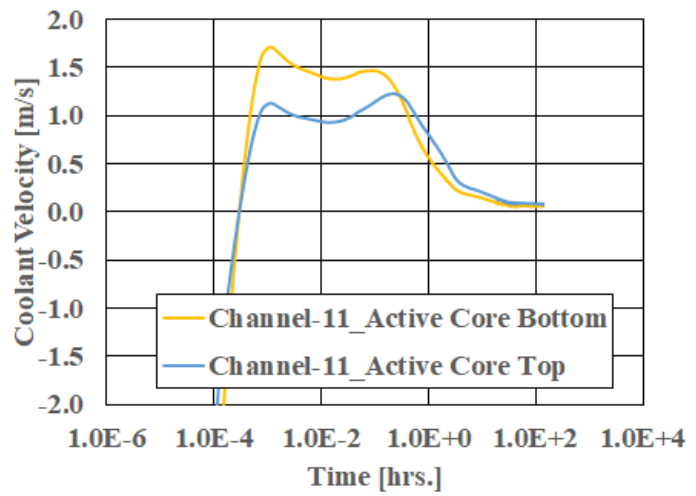

(i)

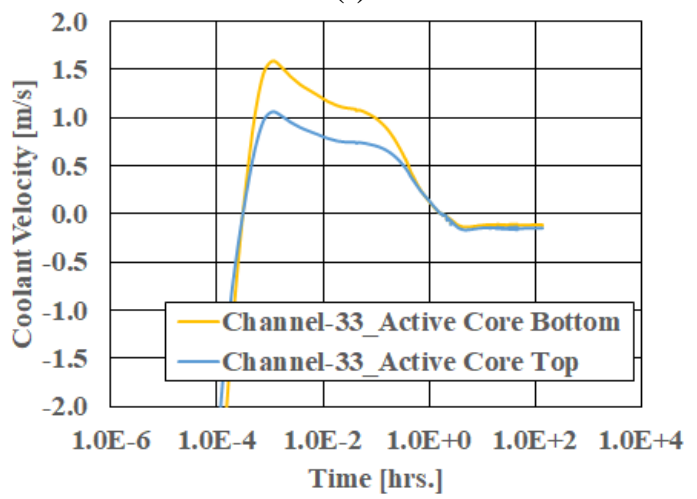

(iii)

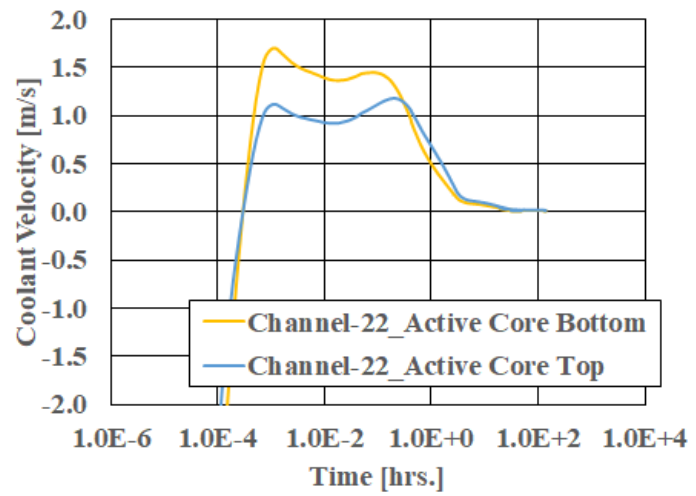

(ii)

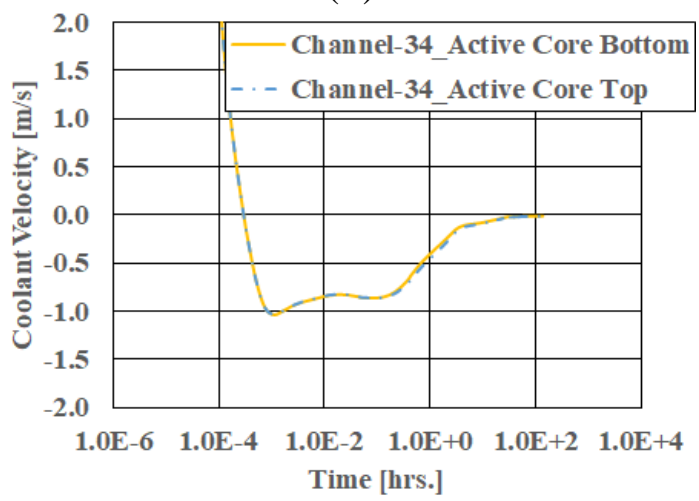

(iv)

Figure 2-23. Coolant channel velocities for (i) inner fuel ring, (ii) middle fuel ring, (iii) outer fuel ring and (iv) RPV 


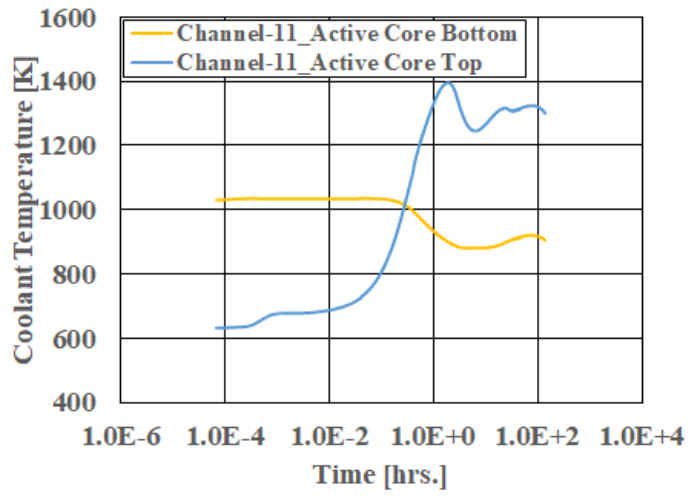

(i)

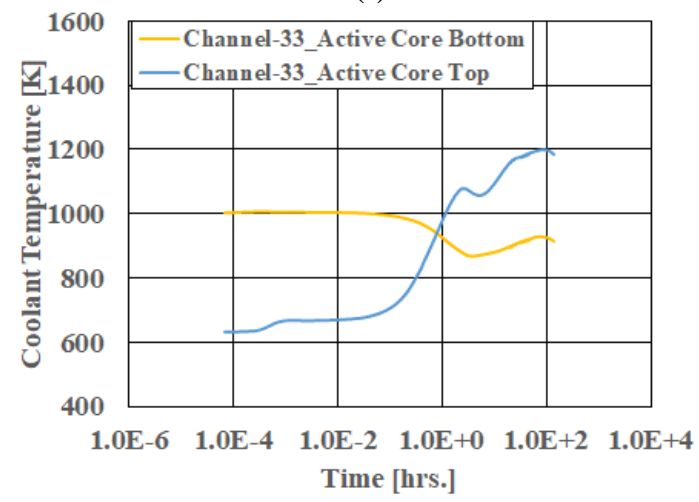

(iii)

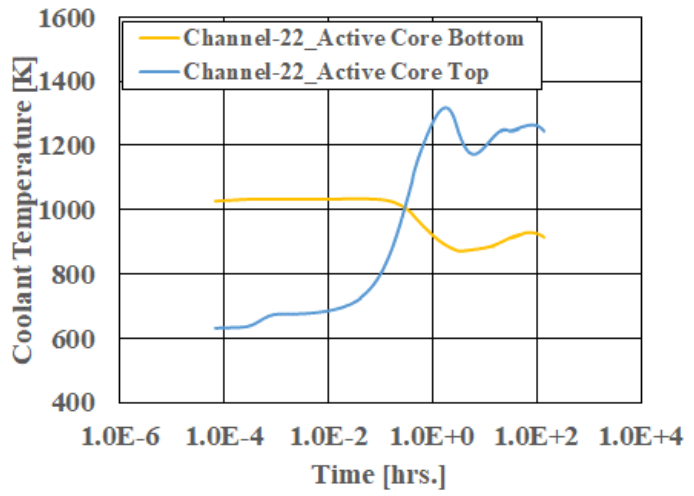

(ii)

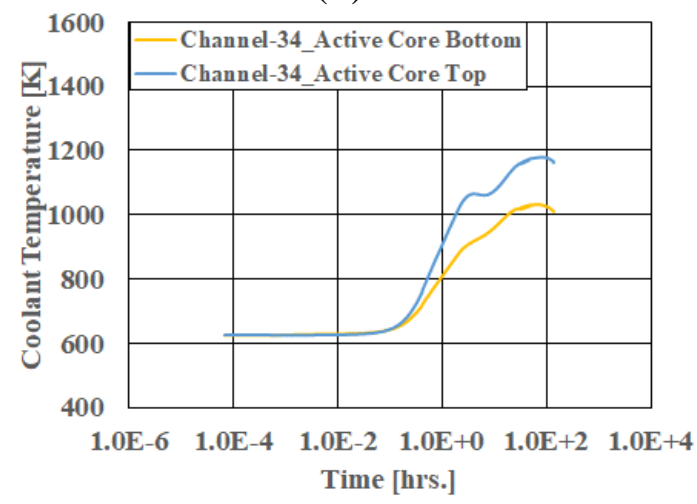

(iv)

Figure 2-24. Coolant channel temperatures for (i) inner fuel ring, (ii) middle fuel ring, (iii) outer fuel ring and (iv) RPV

As seen in Figure 2-25, the heat removal from RCCS increased up to $94 \mathrm{hrs}$. Further increasing the time, the heat removal drops due to the decrease of vessel wall temperature. The maximum heat removal was calculated around 3.15 MW from RCCS (table 2-6), although the heat removal surpassed the reactor power around $28 \mathrm{hrs}$.

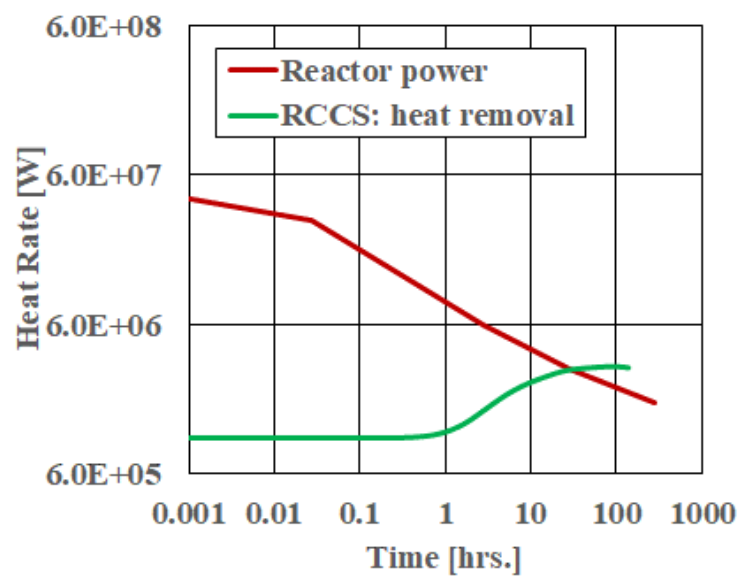

Figure 2-25. RCCS heat removal and reactor power 


\subsection{Conclusions}

A standard SAM HTGR problem was developed in this work based on GA's MHTGR design to assess SAM code capabilities for the primary loop simulations of HTGR. It is noted that integraleffects standard problems are foundational to the methodologies employed by the industry user community to verify the adequacy of computer codes and evaluation models. Two model approaches were developed in SAM to simulate the reactor core, i.e. unit-cell approximation or ring model. Both approaches includes the lower and upper plenum, heat exchanger and blower components for primary loop simulations. In both approaches, the coolant channels and the heat structures were modeled using 1-D and 2-D components, respectively.

Under normal operating conditions, the SAM calculated results for coolant and heat structure temperatures and coolant velocities were within the reactor designed limits. The calculated RCCS heat removal was around $1.048 \mathrm{MW}$. Under the pressurized conduction cooldown accident scenario, the SAM calculated results for coolant and heat structures temperatures were still within the designed limits. The significant increase of reactor core temperatures was found within 5 hrs of reactor shut down. The natural circulation flow was observed in the primary loop as well as inside the reactor core, due to the much lower temperatures in the outer fuel rings than in the middle and inner fuel rings. The calculated maximum RCCS heat removal was around $3.15 \mathrm{MW}$, about three times of heat removal at normal operating conditions.

No obvious gaps in code capabilities were identified for the two test cases: power transient and pressurized conduction cooldown event. It is confirmed that the SAM simulations using the detailed ring model can accurately model the convection-dominant in-core heat-removal during normal operating conditions and conduction-dominant heat-removal during PCC transient conditions. On the other hand, the single-channel unit-cell approach is appropriate for convection dominant regime simulations because of its superior execution speed. 


\section{Modeling and Validation of Deteriorated Turbulent Heat Transfer in Wall Heated Cylindrical Tube}

\subsection{Background}

The Deteriorated Turbulent Heat Transfer (DTHT) can be encountered in a nuclear system during transients. In particular, the Generation IV gas-cooled reactor has a possibility to operate in the DTHT regime during loss of forced circulation flow or due to blower trip off conditions [1]. In Lee et al. [3], experiments were conducted to study the DTHT regime in gas up-flow. The DTHT regime is defined as the deterioration of normal turbulent heat transport due to acceleration and buoyancy effects and it induces a significant reduction of the fluid's heat transfer capability. In their paper, the detailed description of the experimental facility was provided. Both the acceleration driven DTHT and the buoyancy driven DTHT showed a reduction of heat transfer coefficient of up to $70 \%$ compared to the normal turbulent heat transfer. The details of the buoyancy and the acceleration forces on the flow patterns in a wall-heated flow were discussed in the following paragraphs.

The buoyancy effect on the flow depends on the flow orientation and heating direction such as from wall to fluid or from fluid to wall [1-3]. In Lee et al. [3], the work they focused was on upward wall heated flows. In laminar flow, the buoyancy force produces a steeper velocity gradient near the heated wall than in the normal forced flow, resulting in more pronounced heat convection near the wall. In the turbulent flows, the buoyancy force accelerates the flow near the wall more compared to bulk flow, which alters the normal turbulent velocity profile. Hence, shear stress on the fluid elements near the wall decreases due to the velocity profile modification, and the turbulence generation reduction follows the deterioration of the wall shear stress.

An acceleration effect is induced by a fluid density change in stream-wise direction. As the fluid bulk temperature along the heated channel increases, the gas density is reduced in the flow direction. The gas density decrease is accompanied by the bulk velocity rise to satisfy the mass continuity, which is the stream-wise acceleration of the flow. The flow acceleration in stream-wise direction decreases the turbulence of the flow [3]. Hence, the turbulent flow behaves similarly to the laminar flow.

Lee et al. [3] conducted several experiments to investigate the DTHT phenomena for gas upflow in a wall-heated cylindrical tube. In their paper, the detailed description of the experimental facility is provided, and the data were collected for three different gases, i.e., nitrogen, helium and carbon dioxide. The nitrogen experiments were covered for both the acceleration and the buoyancy driven DTHT regimes. The helium experiments were covered for the mixed convection laminar, acceleration driven DTHT and laminar to turbulent transition regimes. Finally, the carbon dioxide experiments were covered for the returbulizing buoyancy driven DTHT and non-returbulizing buoyancy induced DTHT.

The DTHT predicting capability using Computational fluid Dynamics (CFD) tools can help to address the Pressurized Conduction Cooldown (PCC) phenomena in gas-cooled reactors. The Verification and Validation $(\mathrm{V} \& \mathrm{~V})$ of CFD tools are required to select the state-of-the-art CFD models to design thermal efficient reactors. In our previous work [5], upper plenum simulations were validated with the experimental data of Texas A\&M University (TAMU) $1 / 16^{\text {th }}$ scaled Very High Temperature Reactor (VHTR). Currently, the main focus is on V\&V of DTHT phenomena in coolant channels under PCC event. Further, the identified best practice numerical methods and 
CFD tools will be integrated to simulate a full gas-cooled reactor in future course of work. To be noted, the PCC mainly occurs due to loss of forced circulation in gas-cooled reactors which leads to Buoyancy-driven natural circulation flow.

In the present work, numerical simulations were performed to validate the numerical models with experimental data. The outline of the Section is as follows. In Section 3.2, the modeled geometry was presented. Section 3.3, covers the numerical modeling of non-isothermal gas upflow. The grid independent study was presented in Section 3.4. The results were discussed in Section 3.5. Finally, conclusions were discussed.

\subsection{Modeled Geometry}

As seen in Figure 3-1, the experiment loop connecting $~ 2 \mathrm{~m}$-long heated section with elevated cooler and has an overall height of $7 \mathrm{~m}$ spreading over 2 floors to maximize a natural circulation capability. The first system was the main loop, where most of the measurements were made. The main loop further divided into three sections - test section, chimney section and downcomer section. The details of the main loop can be found in Lee et al. [3]. The diameter of the test section was considered $15.748 \mathrm{~mm}$. The loop was designed to operate at pressures of $1 \mathrm{MPa}$ and wall temperature of $1000 \mathrm{~K}$ [3]. The objective of this work was to validate CFD tools with the test section measured data. As seen in Figure 3-2, simulations were performed only for the test section with an extended inlet and outlet to generate a fully developed flow and to minimize the outlet effects on the test section, respectively. For DTHT benchmark test, the modeling and simulations were performed for a given operating conditions as shown in Table 3-1. In Nek5000, recycling boundary condition was applied to generate a fully developed flow in a short extended inlet section (figure 3-2(ii)). In contrast, a full-length extended inlet (figure 3-2(i)) simulations were performed for STAR-CCM+ due to low mesh count compared to Nek5000.

Nek5000 [12] is a high-resolution and highly-scalable open-source transient CFD code developed at Argonne National Laboratory. The code is based on the spectral element method and it was written in FORTRAN 77 and C languages. On the other hand, the STAR-CCM+ [13] is a paid licensed CFD code and it has all options on one platform including Graphical User Interface (GUI), geometry, mesh, numerical models and post processing tools. 


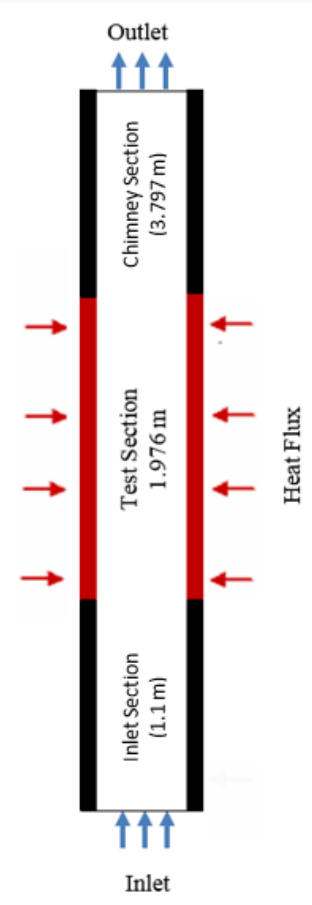

Figure 3-1. Schematic diagram of DTHT benchmark test

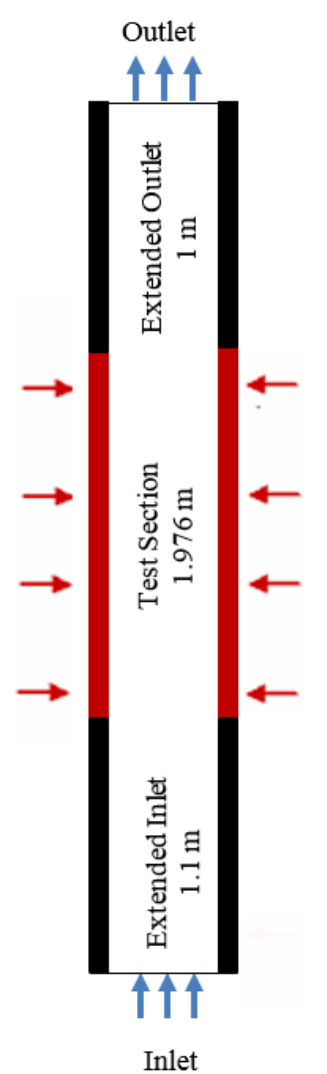

(i)

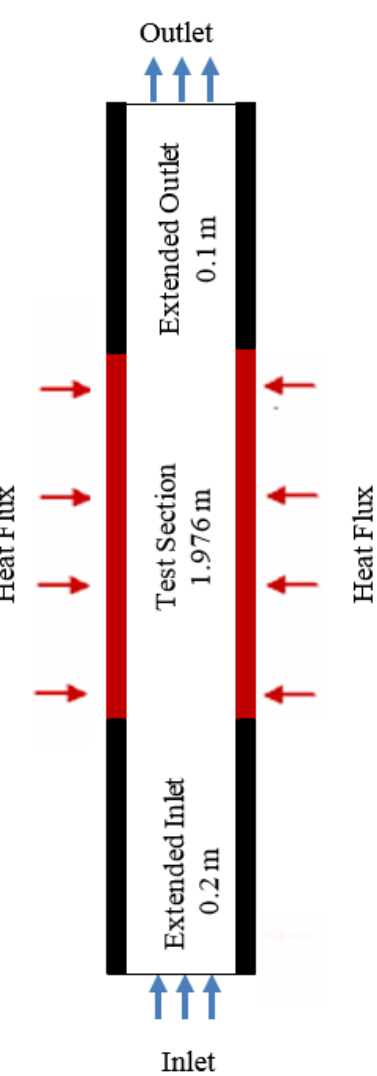

(ii)

Figure 3-2. Modeled geometry for DTHT benchmark test; (i) STAR-CCM+ and (ii) Nek5000 
Table 3-1. DTHT benchmark test operating conditions for inlet temperature of 304 K [3-4]

\begin{tabular}{|c|c|c|}
\hline RUN & $\begin{array}{c}\text { Reynolds Number (Re) } \\
\text { at inlet }\end{array}$ & $\begin{array}{c}\text { Wall heat } \\
{\left[\mathbf{W} / \mathbf{m}^{\mathbf{2}}\right]}\end{array}$ \\
\hline 4 & 8927 & 9356 \\
6 & 6716 & 5572 \\
7 & 6667 & 4675 \\
\hline
\end{tabular}

\subsection{Numerical Modeling}

3D CFD modeling and simulations were performed using STAR-CCM+ and Nek5000. The STAR-CCM+ code uses the Finite Volume (FV) method and the Nek5000 uses the Spectral Element Method (SEM) to solve the Navier-Stokes fluid flow equations, numerically (Table 3-2). In STAR-CCM+, the velocity and Reynolds Stress Model (RSM) turbulence equations were solved using compressible, steady state, real gas, non-isothermal, segregated flow solver [13]. In Nek5000, the velocity equations were solved using low Mach approximation, transient, real gas, non-isothermal, Helmholtz solver [12]. In this work, simulations were performed until the specified convergence criteria were met (normalized residual was $10^{-5}$ ).

In STAR-CCM+, polyhedral mesh was generated to simulate the configurations shown in Figure 3(i). The minimum cell edge size was set at $0.65 \mathrm{~mm}$ over the solid surface and the maximum cell edge size was allowed up to $2.5 \mathrm{~mm}$ away from the solid surface. Six prism layers were selected over the surfaces with a total thickness of $2 \mathrm{~mm}$. In contrast, hexahedral mesh was generated for Nek5000 simulations as shown in Figure 3(ii). In Nek5000, the full 3D pipe volume was discretized with 55,910,400 Gauss-Legendre-Lobatto (GLL) points, using 5600 slices in the axial direction and 9984 points in each radial cross section with a minimum GLL point size of $0.392 \mathrm{~mm}$ and $0.139 \mathrm{~mm}$, respectively. 


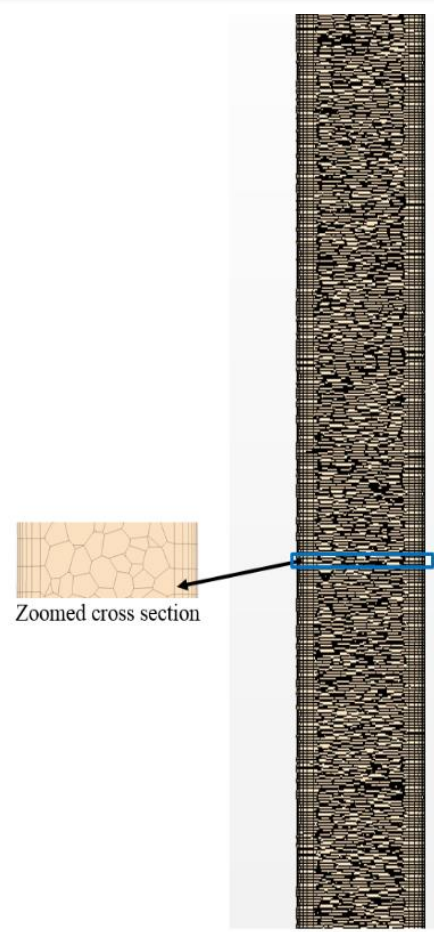

(i)

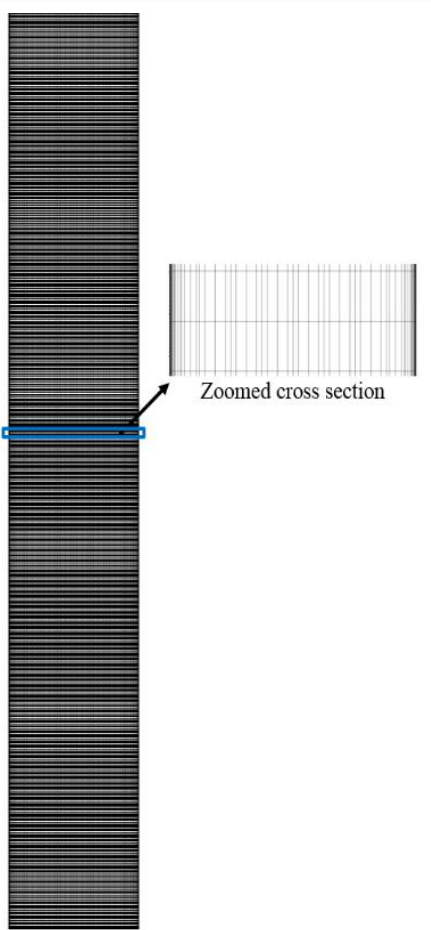

(ii)

Figure 3-3. DTHT cylindrical tube mesh on a vertical plane at center of the tube; (i) STAR$\mathrm{CCM}+$ polyhedral mesh and (ii) Nek5000 hexahedral mesh

Table 3-2. CFD model description for DTHT [4]

\begin{tabular}{|c|c|c|}
\hline & STAR-CCM+- v12.02 & Nek5000 \\
\hline 3D Simulations & Non-isothermal Steady State & Non-isothermal Transient \\
\hline Numerical method & Finite Volume & Spectral Element \\
\hline Turbulence & RSM & LES \\
\hline Gas phase & Nitrogen & Nitrogen \\
\hline Gas model & Real gas & Real gas \\
\hline $\begin{array}{l}\text { Mesh no. of } \\
\text { elements }[\mathrm{M}]\end{array}$ & 0.64 & 55.9 (GLL points) \\
\hline $\begin{array}{l}\text { Numerical accuracy } \\
\text { (order) }\end{array}$ & 2 & 2 \\
\hline $\begin{array}{l}\text { Courant-Friedrichs- } \\
\text { Lewy (CFL) }\end{array}$ & N/A & 0.5 \\
\hline
\end{tabular}

A pressure boundary condition was specified at the outlet, flow velocity and temperature were specified at the inlet, and no-slip boundary condition was imposed at the wall in both CFD codes. In STAR-CCM+ RSM, the linear pressure-strain two-layer option was selected which will reflect 
the realizable two-layer k-epsilon wall functions [13]. On the other hand, the wall-resolved LES was used in Nek5000. In LES, low-pass filtering technique was applied to Navier-Stokes equations to eliminate small scales of the solution in order to reduce the computational cost of the simulation. By doing so, the obtained solution was a filtered flow field [12]. To be noted, the LES formulation relies on slight (5\%) filtering of modes $\mathrm{k}=\mathrm{N}-1$ and $\mathrm{N}$, which provides an energy drain at the unresolved grid scale. The numerical solution was second order accurate in both CFD codes as shown in Table 3-2.

\subsection{Grid Independence Study}

As in Figure 3-4, the DTHT results were validated with three different grids for STAR-CCM+ RSM and Nek5000 LES. The negligible deviations were observed for wall temperature errors between both medium coarse and fine grids. Grid independence study concludes that the medium coarse grid was good enough to validate the CFD models for Run- 6 . Hence, the simulations were performed on the medium coarse grid. In STAR-CCM+, simulations were performed on a polyhedral mesh whereas in Nek5000 simulations were performed on hexahedral mesh, as discussed above.

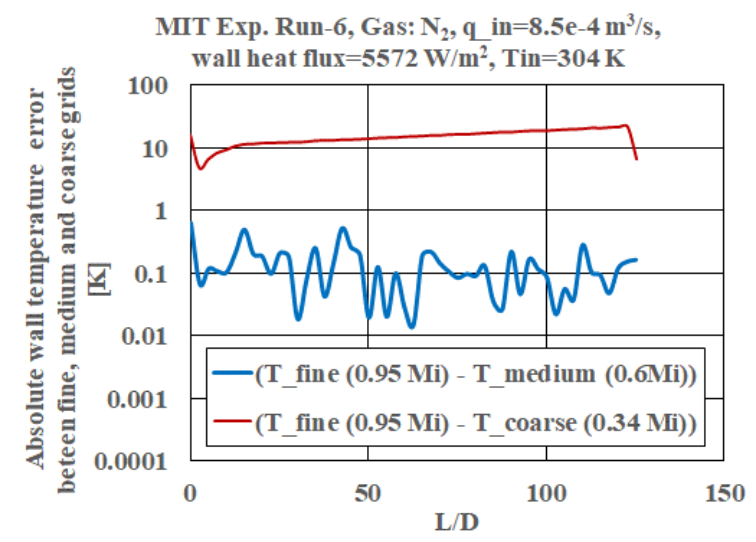

(i)

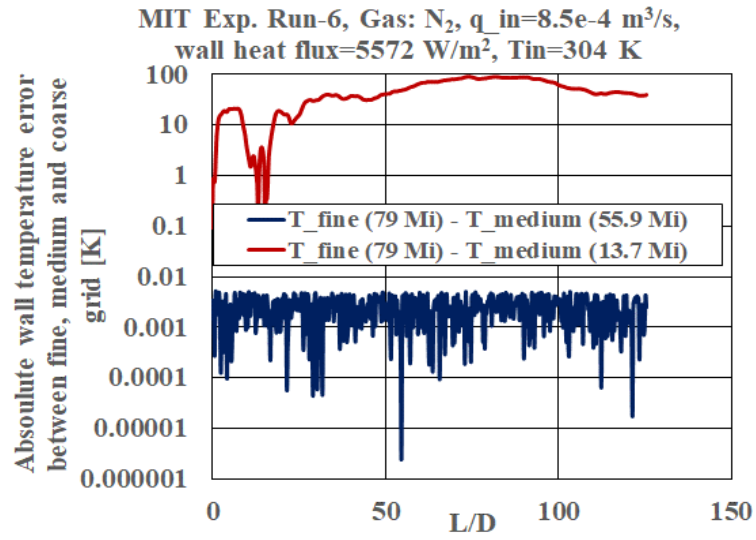

(ii)

Figure 3-4. Comparison of wall temperatures along the axial direction of the test section for different mesh count for Run-6; (i) STAR-CCM+ and (ii) Nek5000

\subsection{CFD Model Validation}

In this section, one DTHT experiment was modeled and simulated for a given operating conditions as highlighted in Table 3-1. For Run-6, both Nek5000 (LES) and STAR-CCM+ (RSM) CFD models were validated with wall temperature data. For Run-4 and Run-7, only STAR-CCM+ RSM simulations were performed due to fast turnaround time calculations (low mesh count) compared to Nek5000 LES simulations and these results were presented in FY18 [2]. To be noted, the Nek5000 time-steps were limited based on CFL of 0.5.

In Figure 3-5(i), the calculated bulk temperatures were identical in both CFD codes, as expected. In Nek5000 and STAR-CCM+, the predicted L2-norm for wall temperature error (difference between measured and simulation data) were $0.07 \%$ and $1.57 \%$, respectively (figure 3-5(ii)). Good agreement was observed between both measured and calculated wall temperatures using Nek5000 simulations. On the other hand, the under-predicted wall temperatures were observed using STAR-CCM+ RSM. This was mainly due to over-predicted turbulent viscosity 
with the STAR-CCM+ RSM (Figure 3-6). In Nek5000, the turbulent viscosity decreases with an increase of tube height and it was in-line with the DTHT phenomena due to reduced Reynolds numbers towards an outlet. In contrast, the increased turbulent viscosity observed in STAR-CCM+ towards an outlet. In Nek5000, the turbulent viscosities were under-predicted compared to STAR$\mathrm{CCM}+$, except at wall. For Nek5000, the fluid temperature and velocity fields along the vertical plane (XZ) shown in Figure 3-7. The significant velocity rise was observed due to density drop, towards an outlet. Near the wall region, the fluid temperature rise was observed due to constant wall-heat flux boundary condition.

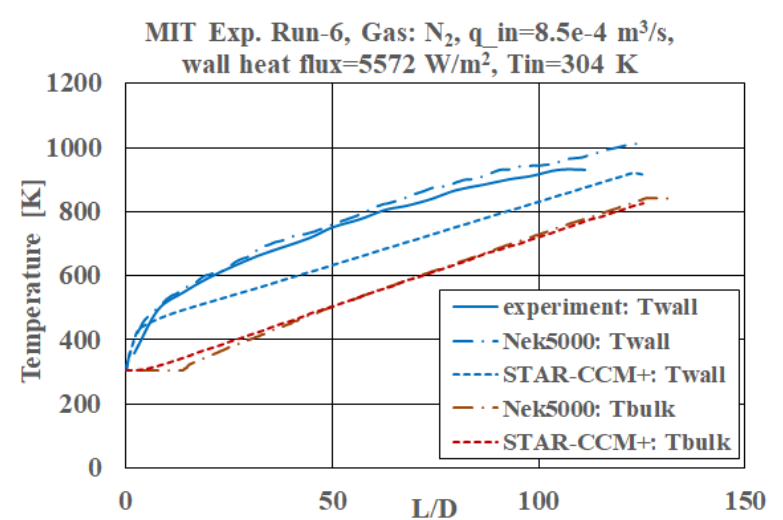

(i)

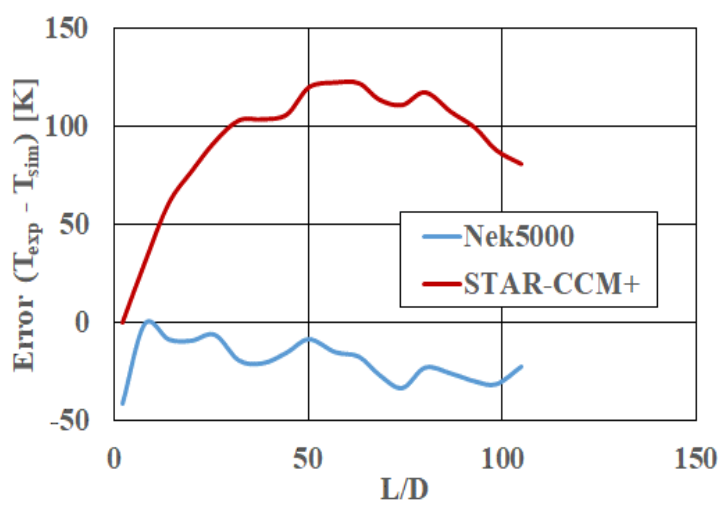

(ii)

Figure 3-5. Comparison of Nek5000 and STAR-CCM+ results with experimental data along the axial direction of the test section; (i) Wall and bulk temperatures and (ii) Simulation error for wall temperature (experiment-simulation)

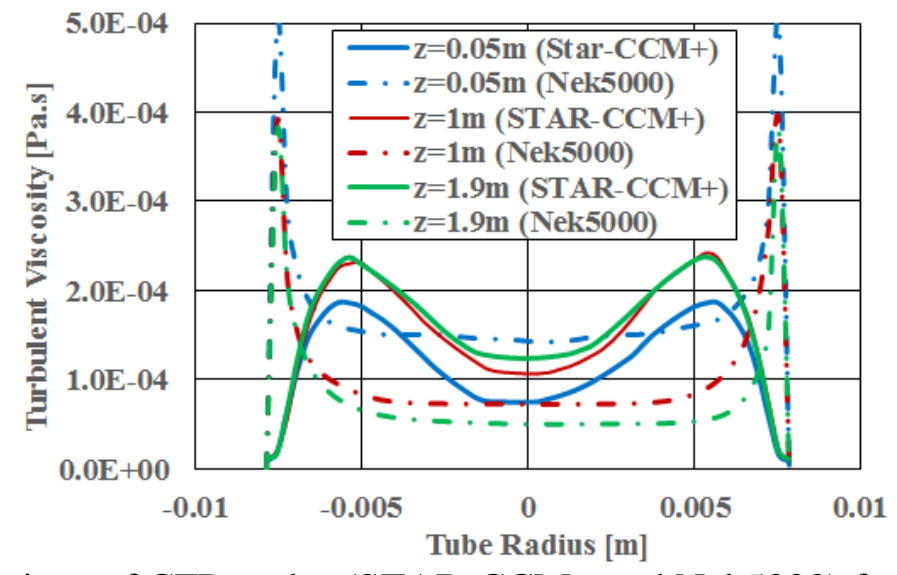

Figure 3-6. Comparison of CFD codes (STAR-CCM+ and Nek5000) for turbulent viscosity across tube radius at various axial locations from test section inlet

As seen in Figure 3-8, velocity profiles were tending towards laminarization (parabolic nature) in the outlet region $(\sim 1.9 \mathrm{~m})$. It is evident that the acceleration effects were dominant due to rapid change of velocities in the core region. 


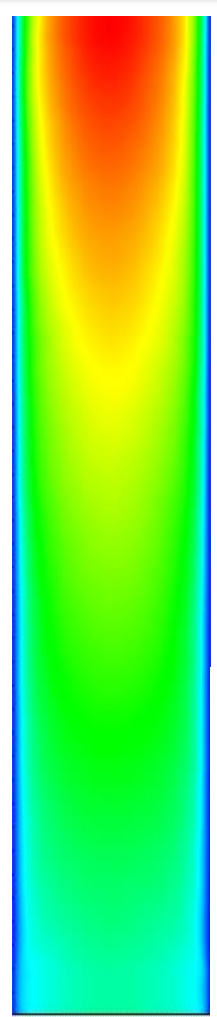

(i)

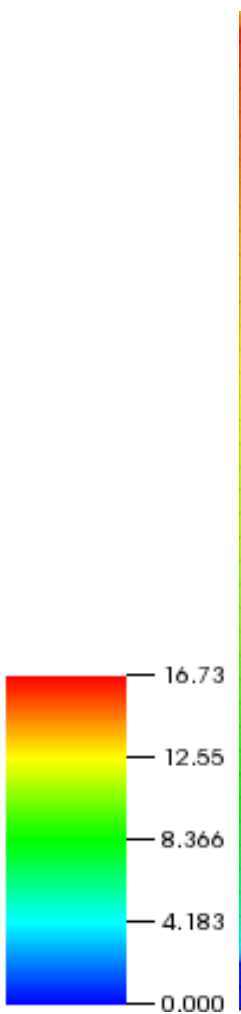

0.000 (ii)

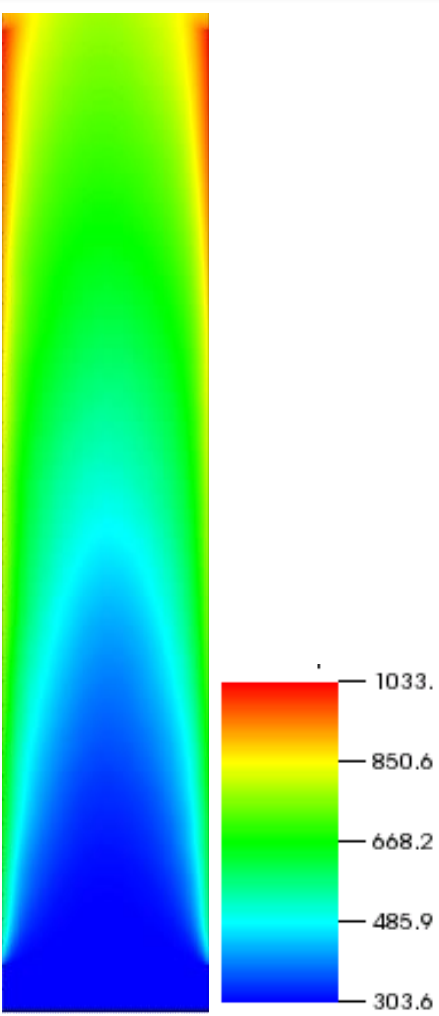

Figure 3-7. Nek5000 time averaged fields on XZ-plane (Y=0) for Run-6; (i) Velocity (m/s) and (ii) Temperature $(\mathrm{K})$

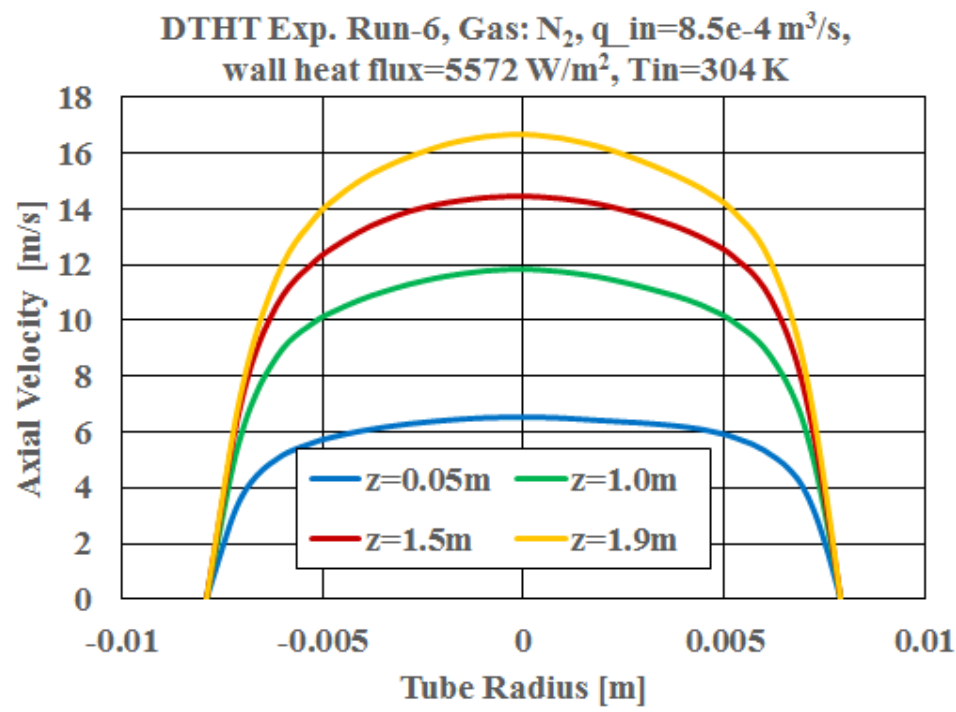

Figure 3-8. Nek5000 axial velocity profiles across radial direction at various axial locations in the test section for Run-6 


\subsection{Conclusions}

3D CFD models were validated with wall temperatures of MIT DTHT benchmark test using both Nek5000 and STAR-CCM+ RSM. Good agreement was observed between both simulated and experiments for wall temperatures using Nek5000. In contrast, wall temperature predictions from STAR-CCM+ were under-predicted for Run-6 due to higher turbulence in the wall region. 


\section{Development of Heat Transfer Correlations for Laminar Flow in Wall Heated Cylindrical Tube}

\subsection{Background}

Heat transfer from wall-to-fluid plays a significant role in gas-cooled reactors to carry heat via fluid. In High Temperature Gas-cooled Reactor (HTGR), the flow would be in the turbulent regime under normal operating conditions. In literature, the predictions of the wall temperatures with turbulent heat transfer correlation reported uncertainties up to $\pm 20 \%$ [14]. Under accident scenarios, the heat transfer correlation validation was shown in Lee et al [14]. Most of their data belongs to upward flow under hypothetical accident scenarios like Pressurized Conduction Cooldown (PCC). To be noted, their experimental data available for higher Reynolds numbers (Re>2000). The PCC was mainly due to the loss-of-forced-circulation due to blower trip-off. The Deteriorated Turbulent Heat Transfer (DTHT) phenomena was observed in their work due to Buoyancy and acceleration driven flow. The uncertainty of heat transfer coefficient was shown up to $70 \%[3,14]$.

In PCC event, the laminar flow can be observed during the development of natural circulation flow. The Reynolds number can approach zero at inflection point where the flow direction changes from forced downward to buyonacy driven upward in coolant channles. Hence, the laminar flow plays a significant role. This work includes the development and validation of heat transfer correlations for laminar flow using Nek5000 CFD code.

3D CFD non-isothermal modeling and simulations were performed in a wall-heated circular tube. The simulations were verified with two different CFD tools, Nek5000 and STAR-CCM+, and validated with an experimental data (see Section 3). In Nek5000 and STAR-CCM+, the predicted L2-norm values for wall temperature error (difference between measured and simulation data) were $0.07 \%$ and $1.57 \%$, respectively. Hence, the Nek5000 code was selected to run simulations for extremely low Reynolds numbers (2000 to 200) to develop the heat transfer correlations.

In current work, the main focus was on development of heat transfer correlations for low Reynolds $(\operatorname{Re}<2000)$ flow. The laminar flow can observed due to the flow changes from forceddownward to Buoyancy-driven upward flow during the development of natural circulation flow, as discussed above in Section 2. Several simulations were performed for various Reynolds number and wall-heat fluxes to develop and validate wall-heat transfer correlations. The mixed-convection heat transfer regime observed for laminar flow. The heat transfer was increased up to $13 \%$ compared to fully-developed flow, Lee et al [14] and Sieder-Tate correlations [15]. To be noted, the Sieder-Tate correlation was valid only at tube entrance length. A new set of heat transfer correlations were proposed for laminar flow (Table 4-2). Towards an outlet, the flow was not yet fully developed condition even though applied a fully-developed conditions at inlet. This was mainly due to flow profile modification (Figure 3.8) with the provided wall-heat flux condition.

Sieder-Tate correlation [15]:

$$
\begin{aligned}
& N u=1.86 \beta \\
& \beta=\boldsymbol{P} e^{1 / 3}\left(\frac{D}{L}\right)^{1 / 3}\left(\frac{\mu_{\text {bulk }}}{\mu_{\text {wall }}}\right)^{0.14}
\end{aligned}
$$




\subsection{Modeling}

The modeled geometry was shown in Figure 3.2(ii). The modeling and simulations were performed for a given operating conditions as shown in Table 4-1. In Nek5000, the parabolic velocity profile was applied at inlet for laminar flow. The details of CFD models, grid independent study and CFD validation with the measured data were shown in Section 3.

Table 4-1. DTHT benchmark test operating conditions for inlet temperature of $304 \mathrm{~K}$

\begin{tabular}{|c|c|c|}
\hline CASE & Re & $q_{\text {wall }}\left[\mathrm{W} / \mathrm{m}^{2}\right]$ \\
\hline $1-3$ & 200 & $2000,5000,7000$ \\
$4-6$ & 400 &, \\
$7-9$ & 1000 &, \\
$10-12$ & 2000 &, \\
\hline
\end{tabular}

\subsection{Wall Heat Transfer Correlation}

The wall-heat transfer corrleations were developed using Nek5000 simulation matrix (Table 4-1) for laminar flow ( $\operatorname{Re}=200$ to 2000). In Figure 4-1(i), the Sieder-Tate correlation was valid only at tube entrance length as discussed above. The fully-developed flow $\mathrm{Nu}$ for cylindrical tube is 4.36. At outlet, the calculated $\mathrm{Nu}$ was up to $13 \%$ higher than the fully-developed correlations. In Figure 4-1(ii), the Nek5000 Nu data plotted shown for various $\beta$ values. The $\beta$ is a function of Péclet, aspect ratio and ratio of bulk to wall fluid viscosity as similar to Sieder-Tate laminar flow correlation (Eqs.1-2).

In Table 4-2, the newly developed wall-heat transfer correlation and $\mathrm{R}^{2}$ value were shown for laminar flow (Figure 4-2). The Nek5000 Nu data (Figure 4-1(ii)) were split into two different data sets for better model fit (Figure 4-2). The $\mathrm{R}^{2}$ values were calculated based on Eq. 3. To be noted, the correlation and numerical data are identical if $R^{2}=1$. On the other hand, the correlation doesn't represents the numerical data if $\mathrm{R}^{2}=0$.

For $\operatorname{Re}>400$ and $\operatorname{Re}<2000$, the predicted $\mathrm{R}^{2}$ value was around 0.95 (Table 4-2 and Figure 42(i)) and thus the correlation represents $95 \%$ of Nek5000 numerical data. On the other hand, the Sieder-Tate correlation shown significant deviations when compared the data of Nek5000 and newly developed correlation (Figure 4-2(i)).

For $\mathrm{Re} \leq 400$, the low $\mathrm{R}^{2}$ value (not shown) was predicted due to numerical scattered data (Figure 4-2(ii)). Further detailed analysis is needed to identify the physics behind the scattered data. Hence, the wall-heat transfer correlation was not shown in this report.

$$
R^{2}=\frac{\sum_{i=1}^{n}\left(y_{i}-\tilde{y}\right)^{2}}{\sum_{i=1}^{n}\left(f_{i}-\tilde{y}\right)^{2}}
$$

where, $y_{i} f_{i}$, and $\tilde{y}$ are sample value, predicted or modeled value and sample mean, respectively.

Table 4-2. Wall heat transfer correlations

\begin{tabular}{|c|c|}
\hline $\begin{array}{c}\mathrm{Re}>400 \& \mathrm{Re}<2000 \\
\left(\mathrm{R}^{2}=0.958\right)\end{array}$ & $\mathrm{Nu}=4.36-0.0066 \beta^{3}+0.1737 \beta^{2}-0.146 \beta$ \\
\hline
\end{tabular}




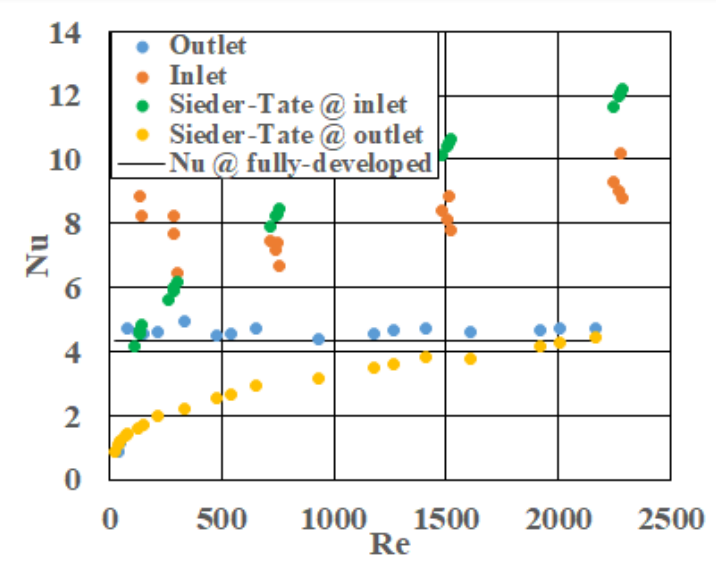

(i)

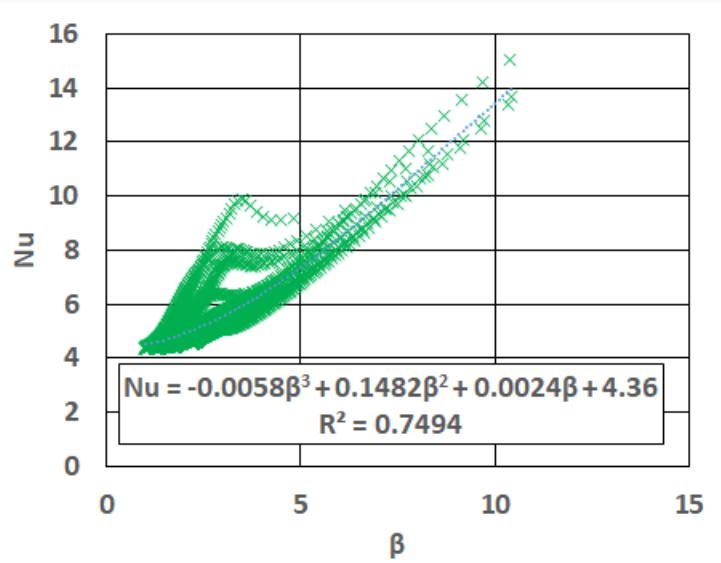

(ii)

Figure 4-1. Nek5000 simulation data; (i) Nusselt Vs. Reynolds flow and (ii) Nusselt Vs. $\beta$ in a wall-heated cylindrical tube

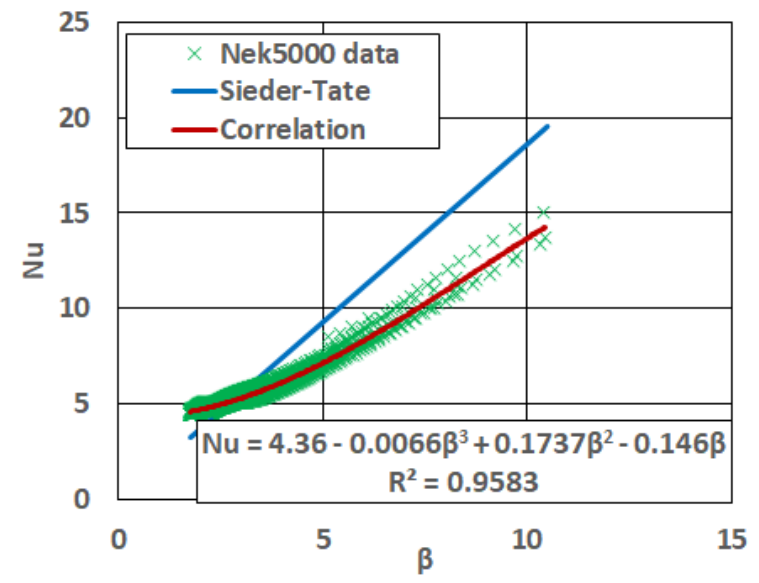

(i)

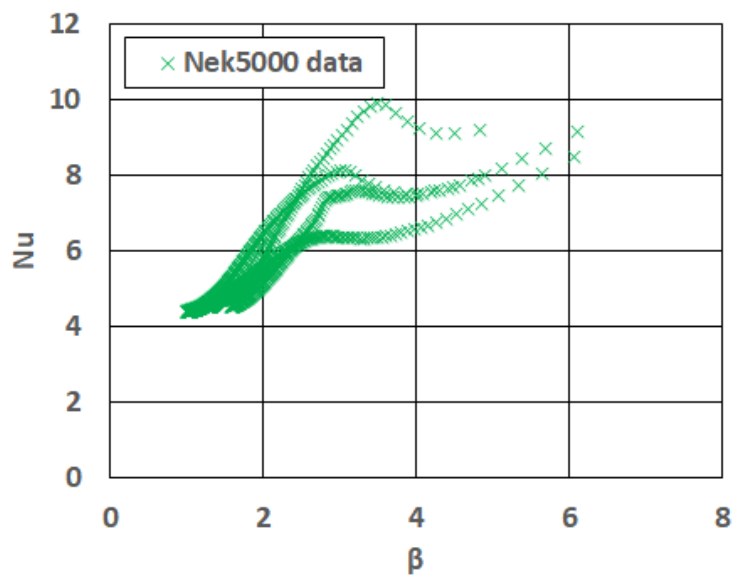

(ii)

Figure 4-2. Wall heat transfer correlations (Nusselt Vs. $\beta$ ), (i) $\operatorname{Re}>400 \& \operatorname{Re}<2000$ and (ii) $\operatorname{Re}$ $\leq 400$ and $\operatorname{Re} \geq 80$

\subsection{Conclusions}

The Nek5000 CFD code was used to develop wall-heat transfer correlations for laminar flows. Several simulations were performed for flow in cylindrical geometries with various Reynolds numbers and wall-heat fluxes. Significant deviations were found when compared the predicted heat transfer coefficient and Sieder-Tate correlation.

The future work includes implementation of recently developed heat transfer correlation in lower order models (such as SAM code) to compare with available literature correlations. Furthermore, the primary loop simulations are planned for MHTGR using the newly developed heat transfer correlations. 


\section{FUTURE WORK}

Future work will continue to assess and apply the advanced modeling capabilities being developed under DOE-NE's Modeling and Simulation program to address key problems identified by the DOE-NE's Advanced Reactor Technology program or industry as important to design and safety performance of HTGRs. To improve the current study, we would continue focusing on thermal fluids phenomena in PCC event and developing the friction factor correlations for natural circulation regime using Nek5000 CFD code. The Nek5000 simulations can be performed to validate with the recently published measured data of $1 / 16^{\text {th }}$ scaled VHTR upper plenum for single jet flows which was selected for ASME V\&V 30 benchmark problem. These simulations can be used as a numerical benchmark test for verification of ongoing developments in lower-order codes such as Pronghorn.

To improve the current primary loop simulation of MHTGR during transient conditions, we could include the heterogeneous modeling of heat structures within the fuel assembly for graphite, clad and fuel to avoid homogeneous assumption for fuel assemblies used in the current work. Furthermore, RCCS modeling can be improved by explicitly simulating the natural circulation air flow. The developed heat transfer correlations using Nek5000 for laminar flow can be implemented in SAM and tested with MHTGR primary loop simulations using newly developed correlations.

Other efforts would include continued engagements with industry on advanced modeling and simulation needs of HTGR, and to perform early demonstration of interested problems. Multiscale modeling and simulation will also be pursued for thermal-hydraulic and safety performance

analysis of advanced reactors by using and integrating engineering-scale simulation tools like Pronghorn, 1-D system analysis code like SAM, along with 3-D tools like Nek5000. 


\section{ACKNOWLEDGEMENTS}

This work was funded by the U.S Department of Energy, Office of Nuclear Energy, Nuclear Energy Advanced Modeling and Simulation (NEAMS) program, under Argonne contract DEAC02-06CH11357.

We gratefully acknowledge the computing resources provided on Bebop and Mira, a highperformance computing cluster operated by the Laboratory Computing Resource Center (LCRC) and Argonne Leadership Computing Facility (ALCF) at Argonne National Laboratory.

\section{NOTATION}

$\begin{array}{ll}\mathrm{D} & \text { Tube diameter }[\mathrm{m}] \\ \mathrm{L} & \text { Tube Length }[\mathrm{m}] \\ \mathrm{Re} & \text { Reynolds number }[-] \\ \mathrm{Pe} & \text { Peclet number }[-] \\ \mathrm{Nu} & \text { Nusselt number }[-] \\ \mathrm{q} & \text { heat flux }\left[\mathrm{w} / \mathrm{m}^{2}\right] \\ \mathrm{G} & \text { mass flux }\left[\mathrm{kg} /\left(\mathrm{m}^{2} \mathrm{~s}\right)\right] \\ \mu & \text { viscosity }[\mathrm{Pa} \mathrm{s}] \\ \text { subscripts } \\ \mathrm{b} & \text { bulk } \\ \mathrm{w} & \text { wall }\end{array}$

\section{References}

1. R. Schultz et al., "Identification and characterization of thermal fluid phenomena associated with selected operating/accident scenarios in modular high temperature gascooled reactors". Idaho National Laboratory, INL/EXT-17-43218 (2017).

2. P. Vegendla et al., "Modeling and simulations of thermal-fluid phenomena related to pressurized conduction cooldown in high temperature gas reactor". Argonne National Laboratory, ANL-18/33 (2018).

3. J.I. Lee et al., "Deteriorated Turbulent Heat Transfer of Gas Up-flow in a Circular Tube: Experimental data," International Journal of Heat and Mass Transfer, 51(1-2): p. 32593266 (2008).

4. P. Vegendla et al., Modeling and simulations of deteriorated turbulent heat transfer in wall heated cylindrical tube, ASME Verification and Validation Symposium, Las Vegas, May 2019.

5. P. Vegendla et al., Modeling and simulations of 1/16th scaled VHTR upper plenum, Int. Topical Mtg. on Advances in Thermal Hydraulics: Embedded Topical Mtg. Orlando, Florida, Nov 2018.

6. R. Hu, SAM Theory Manual, Argonne National Laboratory, ANL/NE-17/4, March 2017.

7. R. Hu, L. Zou, G. Hu, SAM User's Guide, Argonne National Laboratory, ANL/NSE-19/18, Argonne, IL, August 2019.

8. HTGR technology course for the nuclear regulatory commission. Module 5a, "Prismatic HTGR core design description". Idaho National Laboratory, May 24-27, 2010. 
https://art.inl.gov/NGNP/INL\%20Documents/NRC\%20Training\%20Presentations/Modul e\%205a\%20-\%20Prismatic\%20HTGR\%20Core\%20Design\%20Description.pdf

9. G. Strydom et al., "Comparison of the PHYSICS/RELAP5-3D ring and block model results for phase I of the OECD/NEA MHTGR-350 benchmark, Nuclear Technology, Vol 193, 15-35, 2016.

10. P. Vegendla et al., Modeling and simulations of HTGR during pressurized conduction cooldown transients using SAM code, 2019 American Nuclear Society Winter Meeting and Nuclear Technology Expo, Washington DC, Nov 2019.

11. Decay heat removal and heat transfer under normal and accident conditions in gas cooled reactors. IAEA-TECDOC-757, ISSN 1011-4289, Proceedings of a specialists meeting, Julich, Germany, 6-8 July 1992.

12. P. FISCHER et al., Petascale algorithms for reactor hydrodynamics, J. Phys. Conf. Series, (2008).

13. STAR-CCM+-v9.06.011, User Guide (2014).

14. J.I. Lee et al., Deteriorated turbulent heat transfer of gas up-flow in a circular tube: Heat Transfer Correlations, International Journal of Heat and Mass Transfer, 51(1-2): p. 53185326 (2008).

15. E.N. Sieder et al., Heat transfer and pressure drop of liquids in tubes, Industrial Engineering Chemistry, 28 p. 1429-1435 (1936). 


\section{Appendix A}

Table A-1. SAM ring model details for component names (Table 3-1), outer radius and thickness [L: Left Side, R: Right Side, C: Coolant channel].

$\begin{array}{lrr}\text { \#Ring Name } & \text { \#outer radius [m] } & \text { \#width [m] } \\ \text { R-1 } & 1.48 & 1.48 \\ \text { Gap-1 } & 1.482 & 0.002 \\ \text { R2-1-L } & 1.498229683 & 0.016229683 \\ \text { R2C-1 } & 1.498250709 & 2.1026 \mathrm{E}-05 \\ \text { R2-1-R } & 1.514306234 & 0.016055525 \\ \text { R2-2-L } & 1.530193306 & 0.015887072 \\ \text { R2C-2 } & 1.530213893 & 2.05868 \mathrm{E}-05 \\ \text { R2-2-R } & 1.545937495 & 0.015723603 \\ \text { R2-3-L } & 1.561502777 & 0.015565282 \\ \text { R2C-3 } & 1.561522951 & 2.0174 \mathrm{E}-05 \\ \text { R2-3-R } & 1.576934402 & 0.015411451 \\ \text { R2-4-L } & 1.592196688 & 0.015262285 \\ \text { R2C-4 } & 1.592216473 & 1.97851 \mathrm{E}-05 \\ \text { R2-4-R } & 1.607333655 & 0.015117182 \\ \text { R2-5-L } & 1.622309977 & 0.014976322 \\ \text { R2C-5 } & 1.622329395 & 1.94178 \mathrm{E}-05 \\ \text { R2-5-R } & 1.637168546 & 0.014839151 \\ \text { R2-6-L } & 1.6518744 & 0.014705853 \\ \text { R2C-6 } & 1.65189347 & 1.90703 \mathrm{E}-05 \\ \text { R2-6-R } & 1.666469388 & 0.014575917 \\ \text { R2-7-L } & 1.680918916 & 0.014449529 \\ \text { R2C-7 } & 1.680937657 & 1.87408 \mathrm{E}-05 \\ \text { R2-7-R } & 1.69526387 & 0.014326213 \\ \text { R2-8-L } & 1.709470027 & 0.014206157 \\ \text { R2C-8 } & 1.709488455 & 1.84278 \mathrm{E}-05 \\ \text { R2-8-R } & 1.723577373 & 0.014088918 \\ \text { R2-9-L } & 1.737552055 & 0.013974682 \\ \text { R2C-9 } & 1.737570185 & 1.813 \mathrm{E}-05 \\ \text { R2-9-R } & 1.751433221 & 0.013863037 \\ \text { R2-10-L } & 1.765187387 & 0.013754166 \\ \text { R2C-10 } & 1.765205233 & 1.78461 \mathrm{E}-05 \\ \text { R2-10-R } & 1.778852917 & 0.013647683 \\ \text { R2-11-L } & 1.792396687 & 0.01354377 \\ \text { R2C-11 } & 1.792414262 & 1.75752 \mathrm{E}-05 \\ \text { R2-11-R } & 1.805856326 & 0.013442064 \\ \text { Gap-2 } & 1.807856326 & 0.002\end{array}$


R3-1-L

R3C-1

R3-1-R

R3-2-L

R3C-2

R3-2-R

R3-3-L

R3C-3

R3-3-R

R3-4-L

R3C-4

R3-4-R

R3-5-L

R3C-5

R3-5-R

R3-6-L

R3C-6

R3-6-R

R3-7-L

R3C-7

R3-7-R

R3-8-L

R3C-8

R3-8-R

R3-9-L

R3C-9

R3-9-R

R3-10-L

R3C-10

R3-10-R

R3-11-L

R3C-11

R3-11-R

Gap-3

R4-1-L

R4C-1

R4-1-R

R4-2-L

R4C-2

R4-2-R

R4-3-L

R4C-3

R4-3-R
$1.823838346 \quad 0.015982021$

$1.823855619 \quad 1.72723 \mathrm{E}-05$

$\begin{array}{ll}1.839698654 & 0.015843035\end{array}$

1.8554064130 .015707759

$1.855423391 \quad 1.69784 \mathrm{E}-05$

$1.87099914 \quad 0.015575748$

1.8864462890 .015447149

$1.886462988 \quad 1.6699 \mathrm{E}-05$

$1.901784537 \quad 0.015321549$

1.9169836310 .015199095

1.917000064 1.6433E-05

$1.932079467 \quad 0.015079403$

$1.947042086 \quad 0.014962619$

$1.947058266 \quad 1.61793 \mathrm{E}-05$

1.9619066520 .014848386

$1.976643501 \quad 0.014736849$

1.976659438 1.5937E-05

$\begin{array}{ll}1.99128711 & 0.014627672\end{array}$

$2.00580811 \quad 0.014521$

$2.005823815 \quad 1.57053 \mathrm{E}-05$

2.0202403310 .014416516

$2.034554697 \quad 0.014314366$

$2.034570181 \quad 1.54834 \mathrm{E}-05$

2.048784430 .014214249

2.0629007390 .014116309

$2.06291601 \quad 1.52707 \mathrm{E}-05$

$2.076936273 \quad 0.014020263$

$2.090862526 \quad 0.013926253$

$2.090877592 \quad 1.50664 \mathrm{E}-05$

$\begin{array}{ll}2.104711602 & 0.013834009\end{array}$

$2.118455273 \quad 0.013743672$

$2.118470144 \quad 1.48702 \mathrm{E}-05$

$2.13212513 \quad 0.013654986$

$2.13412513 \quad 0.002$

$2.147680584 \quad 0.013555454$

$2.147695251 \quad 1.46678 \mathrm{E}-05$

$2.161165591 \quad 0.01347034$

2.174552490 .013386899

$2.174566977 \quad 1.44866 \mathrm{E}-05$

$2.187871878 \quad 0.013304902$

$2.201096357 \quad 0.013224479$

$2.201110669 \quad 1.43119 \mathrm{E}-05$

$2.214256082 \quad 0.013145413$ 


\begin{tabular}{|c|c|c|}
\hline R4-4-L & 2.227323914 & 0.013067832 \\
\hline R4C-4 & 2.227338057 & $1.41434 \mathrm{E}-05$ \\
\hline R4-4-R & 2.240329583 & 0.012991526 \\
\hline R4-5-L & 2.253246205 & 0.012916622 \\
\hline R4C-5 & 2.253260186 & 1.39807E-05 \\
\hline$R 4-5-R$ & 2.266103105 & 0.01284292 \\
\hline R4-6-L & 2.278873648 & 0.012770543 \\
\hline R4C-6 & 2.278887472 & $1.38234 \mathrm{E}-05$ \\
\hline R4-6-R & 2.291586771 & 0.012699299 \\
\hline R4-7-L & 2.304216081 & 0.01262931 \\
\hline R4C-7 & 2.304229752 & $1.36714 \mathrm{E}-05$ \\
\hline R4-7-R & 2.316790144 & 0.012560392 \\
\hline R4-8-L & 2.329282806 & 0.012492662 \\
\hline R4C-8 & 2.32929633 & $1.35243 \mathrm{E}-05$ \\
\hline R4-8-R & 2.341722275 & 0.012425945 \\
\hline R4-9-L & 2.354082631 & 0.012360356 \\
\hline R4C-9 & 2.354096013 & $1.33818 \mathrm{E}-05$ \\
\hline R4-9-R & 2.366391738 & 0.012295725 \\
\hline R4-10-L & 2.378623904 & 0.012232166 \\
\hline R4C-10 & 2.378637148 & 1.32437E-05 \\
\hline R4-10-R & 2.390806663 & 0.012169515 \\
\hline R4-11-L & 2.402914547 & 0.012107884 \\
\hline R4C-11 & 2.402927657 & 1.31099E-05 \\
\hline R4-11-R & 2.414974771 & 0.012047114 \\
\hline Gap-4 & 2.416583017 & 0.001608246 \\
\hline$R-5$ & 3.339415889 & 0.922832872 \\
\hline Gap-5 & 3.341415889 & 0.002 \\
\hline R-6 (core barrel) & 3.392500574 & 0.051084685 \\
\hline R-6 (coolant) & 3.487771894 & 0.09527132 \\
\hline R-7 (RPV) & 3.587771894 & 0.1 \\
\hline RCCS & 3.607771894 & 0.02 \\
\hline
\end{tabular}




\section{Argonne}

Nuclear Science and Engineering Division

Argonne National Laboratory

9700 South Cass Avenue, Bldg. 208

Argonne, IL 60439

www.anl.gov

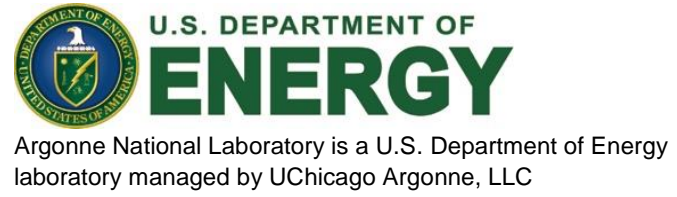

